Check for updates

Cite this: Mater. Adv., 2021, 2, 2561

Received 24th September 2020, Accepted 4th March 2021

DOI: 10.1039/d0ma00732c

rsc.li/materials-advances

\section{Injectable hydrogels in stroke and spinal cord injury treatment: a review on hydrogel materials, cell-matrix interactions and glial involvement}

\author{
Po Hen Lin, ${ }^{a}$ Quanbin Dong ${ }^{\mathrm{b}}$ and Sing Yian Chew (D) *ac \\ Central nervous system (CNS) pathologies, such as stroke and spinal cord injury, remain debilitating \\ issues due to the inhibitory environment in the CNS. Many research works have focused on combinatorial \\ therapeutic approaches, such as biomaterial scaffolding, cell transplantation and biomolecule delivery, in the \\ hope of effectively improving functional recovery in vivo. Unfortunately, to date, there is still no effective \\ treatment to regain mobility post-injury. In search of better therapeutic strategies, injectable hydrogels are \\ becoming a popular treatment option for CNS diseases due to their tuneable mechanical properties and the \\ minimally invasive nature of administration. Moreover, the ability to encapsulate exogenous cells and \\ therapeutic molecules while providing an environment that is permissive to cells and promote cell survival \\ incentivises the use of injectable hydrogels in CNS disease treatment. In this review, we will discuss the \\ advances that have been achieved in the recent decade in injectable hydrogel systems for tissue \\ regeneration after stroke and spinal cord injuries. In particular, we focus on the cellular response and tissue \\ integration related to these hydrogel systems. We hope to provide useful insights on materials choices for \\ future research work in injectable hydrogels for stroke and spinal cord regeneration.
}

\section{Introduction}

Despite advances in medicine and technology, pathologies of the central nervous system (CNS), such as stroke and spinal cord injury (SCI), remain debilitating issues globally. Stroke is one of the main causes of adult disability and the third leading cause of death worldwide. ${ }^{1}$ In the next decade, stroke will continue to increase the burden on patients and society. ${ }^{2}$ By 2030 , approximately 3.4 million Americans are expected to suffer from ischemic stroke, a prevalence increment of $20.5 \%$ as compared to $2012 .^{3}$ In the case of SCI, it is estimated that over 1 million people suffer from SCI in North America. The lifetime costs for treatment and care range from \$1.1 to $\$ 4.7$ million USD per person, which aggregates a direct cost that exceeds $\$ 7$ billion per year in the United States alone. ${ }^{4}$ To date, there is still no effective treatment for CNS diseases. The inhibitory microenvironment in the CNS makes it difficult for self-regeneration to take place. Hence, in search for better therapeutic treatment options, recent studies have focused on the introduction of tissue scaffolds that mimic the extracellular matrix (ECM) to promote regeneration. ${ }^{5-7}$ Correspondingly, a variety of scaffold materials in combination with

\footnotetext{
${ }^{a}$ School of Chemical and Biomedical Engineering, Nanyang Technological University, Singapore 637459, Singapore.E-mail: sychew@ntu.edu.sg

${ }^{b}$ Department of Cardiology, The Second Affiliated Hospital of Nanchang University, 330006, China

${ }^{c}$ Lee Kong Chian School of Medicine, Nanyang Technological University,

Singapore 308232, Singapore
}

various biological agents have been developed. These may include exogenous cells, microRNAs and growth factors. ${ }^{8-15}$

Injectable hydrogels have become a popular scaffolding treatment option for CNS diseases. The tunable mechanical properties and the ability for minimally-invasive administration make injectable hydrogels a more attractive option as compared to other traditional scaffolding methods, which require surgical procedures. While there have been many reviews on injectable hydrogels for stroke and SCI treatments, most of them have focused on the design strategies, particularly the physical and chemical properties of various scaffold materials. ${ }^{5,6,16-20}$ In this review, the advances of injectable hydrogels and cell transplantation for recovery in CNS diseases will be discussed, focusing on the aspect of cellular response and tissue integration. We then assess the suitability of hydrogel materials in different stages of tissue regeneration in vitro and in vivo. We hope that this review will aid the future selection of materials and the development of injectable hydrogels for CNS disease treatment.

\section{Disease pathogenesis and cellular involvement}

\subsection{Stroke and SCI pathology}

Stroke can be divided into haemorrhagic stroke and ischemic stroke. Haemorrhagic stroke is caused by ruptured cerebral blood 
vessels or abnormal blood vessel structures, while ischemic stroke is a result of interruption in blood supply to the brain. Studies have shown that about $85 \%$ of stroke patients suffered from ischemic stroke. ${ }^{21}$ Thus, in this review we will mainly discuss studies related to ischemic stroke. Ischemic stroke is mainly due to the blockage of blood vessels in the brain and the inability of the body to establish reperfusion. Subsequent brain damage stems from a complex series of pathological events, such as depolarization, inflammation, and excitotoxicity. These phenomena greatly impair the stability of the blood-brain barrier and activate the release of free radicals and proteases, which not only causes local neuronal cell death, but also further expands the damage. ${ }^{20}$ Unlike the other organs and tissues, brain tissues are very sensitive to ischemia. The core of the infarct is usually immediately and irreversibly damaged and the related nerve function is immediately lost. Soon after, the core boundary expands to adjacent tissues, resulting in apoptosis and cell death to the distal end of tissues due to vascular occlusion. ${ }^{22}$

The cause of SCI is commonly due to sudden mechanical impact to the spinal cord parenchyma that results in fracture, contusion, compression or laceration of spinal cord tissue. ${ }^{23}$ Following the initial impact on spinal cord tissue, the focal destruction of neural tissue at the lesion triggers a sequence of chronological events that eventually lead to the destruction of neural tracts, also known as secondary injury. Within $15 \mathrm{~min}$ post-injury, multiple hemorrhages are often seen in the grey matters where re-perfusion does not usually occur within the first 24 h. ${ }^{24}$ Following the initial injury, the loss of blood supply and the lack of self-healing mechanism lead to vascular insult, hemorrhages and ischemia which ultimately result in cell death and necrotic tissues within $24-48$ h post-trauma. ${ }^{23,25}$ The native microenvironment of the spinal cord inhibits its ability for selfrecovery as axonal destruction results in filtration of glial cells and other non-CNS cells to clear up the debris. The debris from myelin and oligodendrocytes form the initial component of glial scar to contain further damage, followed by migration and proliferation of astrocytes that upregulate the production of glial fibrillary acidic protein (GFAP) and form the bulk of nonpermissive scar. ${ }^{26}$ The clearing of debris and glial scarring form a cystic cavity at the lesion which acts as a wall to prevent axonal regrowth and neurite outgrowth. ${ }^{6}$ Over time, continuous apoptosis of oligodendrocytes within the lesion leads to further demyelination of axons and Wallerian degeneration. This further creates an environment that prevents axonal regrowth after SCI. ${ }^{5}$

Injuries in the CNS lead to tricky pathologies as self-regeneration and recovery are discouraged in the native CNS microenvironment and axonal regeneration and functional recovery does not occur actively. ${ }^{27}$ Treatments in CNS injuries have focused on restoring secondary injuries and providing structural support and extracellular cues for cell ingrowth and tissue recovery. ${ }^{28}$ The use of injectable hydrogel has become an appealing treatment option due to the capability in providing mechanical support as well as flexibility in shapes and material choices. In SCI, the lesion is further complicated by glial scars formed by reactive astrocytes, leading to further inhibitory barrier that prevents recovery. With regard to the administration approaches, hydrogels could be implanted via open-wound surgery and injection in the SCI model, but limited to the injection method in the stroke model.

\subsection{The roles of glial cells in stroke and spinal cord injury treatment and the potential of cell transplantation}

Glial cells in the CNS, mainly astrocytes, microglia and oligodendrocytes and their progenitors, support and enable effective nervous system function. In the healthy CNS, glia aid in the homeostasis of the microenvironment. While remaining relatively inactive in the healthy state, glial cells act to increase inflammatory actions and help modulate the environment in the event of an infection or injury. These cells play crucial roles in tissue regeneration after CNS pathology by regulating inflammation and supporting neuronal growth. ${ }^{29}$

Reactive astrocytes limit the expansion of the lesion by forming glial scar around the lesion and releasing neurotrophins through anti-excitatory toxicity, thereby providing neuroprotection. ${ }^{30}$ The views on the effects of glial scar remain controversial. Traditionally, the glial scar is believed to prevent axonal regrowth. ${ }^{31}$ However, recent studies have shown that, by preventing glial scar formation, axonal regrowth is reduced in vivo, thus suggesting the potential beneficial effects of astrocytes and glial scarring in axonal regeneration. ${ }^{32}$ Polarization of microglia can be either pro-inflammatory, which produces cytotoxic factors leading to inflammation and oligodendrocyte apoptosis by releasing pro-inflammatory cytokines, or anti-inflammatory reactions that produce trophic factors to promote axon regeneration. ${ }^{33,34}$ In the case of oligodendrocytes, despite the extensive neuronal cell death after CNS injuries, activated oligodendrocyte progenitor cells (OPCs) show significant proliferation and migration to replace lost cells. The interaction with cytokines promotes OPC differentiation into oligodendrocytes to replace dead oligodendrocytes in the lesion and support axon regrowth. ${ }^{35,36}$

Neuron cell death and glial inflammation pose a major challenge in tissue regeneration following CNS injuries. In this regard, cell transplantation has become a popular therapeutic option for the treatment of stroke and SCI due to the potential of (1) directly replacing damaged cells in the lesion, (2) providing neuroprotection to the surviving neuro connective tissues, and (3) providing a supportive cellular growth substrate for axonal regrowth. ${ }^{37}$ However, cell transplantation commonly faces major cell death, low cell migration and integration, as well as limited directional guidance of axonal growth. ${ }^{38,39}$ In addition, the potential safety risks associated with stem cell transplantation require the development of rigorous protocols to ensure cell homogeneity, quality assurance, and no tumorigenicity. ${ }^{40}$

\section{The roles of injectable hydrogels in cellular response and tissue regeneration in stroke and spinal cord injury treatment}

To overcome the challenges faced in tissue regeneration within the CNS, combinations of scaffold materials and cellular and 
molecular therapies have to be considered according to the type and severity of the injury. ${ }^{5,41}$ Injectable hydrogels are widely used to treat pathologies in both hard and soft tissues due to their resemblance to natural ECM structures and minimallyinvasive administration. Some common requirements for injectable hydrogels include biocompatibility and noncytotoxicity. Depending on the types of tissues and application, the rate of degradation, gelation time and mechanical properties of hydrogels need to be carefully considered. ${ }^{42}$ In hard tissue applications, such as bones and cartilages, the mechanical properties of hydrogels are one of the main considerations due to the weight bearing nature of these tissues. ${ }^{43}$ However, the good mechanical properties of hydrogels are difficult to achieve, particularly up to the mega pascal range, without modifications in functional groups or crosslinking which often use cytotoxic agents that affect the cytocompatibility of the hydrogels. ${ }^{44}$ Instead, the viscoelastic nature of injectable hydrogels is more suitable for applications in soft tissues like skin, cardiac tissues and neural tissues. ${ }^{43}$

Injectable hydrogels are viscoelastic materials that are able to fill the irregularly-sized defects in the CNS injuries. They may also facilitate tissue-implant integration and allow modulation of the microenvironment to reduce scarring while promoting regeneration. ${ }^{45-50}$ The use of hydrogels provides a more favorable environment by mimicking the natural ECM structure and/or providing suitable stiffness that supports cell attachment and functionality. ${ }^{51}$ The mechanical properties of hydrogels should be tuned to closely match the native CNS tissues, which possess a mechanical stiffness of about $100 \mathrm{~Pa}$ to $1000 \mathrm{~Pa}$ for both brain and spinal cord tissues, ${ }^{52,53}$ thus allowing primary cell attachment and differentiation towards a neural lineage. As hydrogels are crosslinked with high porosity, they are ideal carriers for neuroprogenitor cells. The potential of differentiating into functional neurons, astrocytes and oligodendrocytes aids in modulation of the microenvironment at the injury site. ${ }^{16}$

Natural polymers are a popular choice of material for injectable hydrogels due to their resemblance to the native CNS tissues. Many contain intrinsic amino acids that can be readily modified for cell adhesion. ${ }^{54}$ Some common materials of choice include collagen, gelatin, hyaluronic acid (HA), chitosan, alginate, agarose and methylcellulose. ${ }^{10,16,55,56}$ Such natural polymers have their inherent advantages as they are typically the components of the ECM, thus making them more biologically active in stimulating cellular functions. ${ }^{57}$ For example, collagen is known to improve cell migration, ${ }^{58} \mathrm{HA}$ is known to directly activate intracellular signalling pathways via $\mathrm{CD} 44$ cell surface receptors $^{59}$ and chitosan is known for its antibacterial properties. ${ }^{60}$ Combining the unique properties from various natural polymers and their inherent characteristics, such as biocompatibility, non-immunogenicity and non-toxicity, cells and host tissues could potentially have a higher chance of survival and proliferation in these hydrogels. ${ }^{61}$

Self-assembling peptides (SAPs) are amino acid-based molecules that undergo sol-gel transition at neutral $\mathrm{pH}$ and ionic concentration to form ECM-like networks. ${ }^{62}$ ECM molecules, growth factors and cells are also frequently incorporated to enhance cell attachment, cell migration and tissue regeneration. ${ }^{6}$ The most suitable time for regeneration to take place post traumatic CNS injury is at the sub-acute stage, i.e., 7-14 days post injury. This is the period when the initial cascade of inflammation starts to take place and the microenvironment is not too harsh for implantation to take place. ${ }^{63} \mathrm{~A}$ brief summary of the use of injectable hydrogels in CNS disease treatment is shown in Fig. 1A.

\subsection{Challenges and advances of injectable hydrogels}

Injectable hydrogels are able to form scaffolds in situ and fill irregular defects to aid in establishing tissue-implant integration. As injuries to the CNS are typically irregular in shapes, the use of injectable hydrogels eliminates the needs for preform scaffolds that require excising viable tissues to accommodate implantation and reduces the risks of scaffold deformation and compression. ${ }^{64,65}$ Scaffold compression may be unfavourable in CNS treatment as it can significantly increase scaffold stiffness beyond theYoung's modulus of the CNS tissues. ${ }^{66}$ In addition, when comparing to traditional scaffolding or nerve guides, injectable hydrogels are typically highly porous with a high proportion of water $(>90 \%)$, making them ideal drugs and cell carriers with a controllable diffusion rate by changing the crosslinking density. A downside would be the high water content that significantly increases the rate of diffusion of hydrophilic drugs out of the hydrogel and could be problematic if prolonged drug release is required. ${ }^{67}$ The in situ gelation property of injectable hydrogels allows the release of molecules in a controlled fashion and prevents drugs from being washed away by the body fluids from the targeted regions. ${ }^{68}$ Lastly, as direct cell transplantation often faced significant cell death, injectable hydrogels are favorable in this context, since these hydrogels can support the survival of exogenous stem cells by allowing modification of scaffold stiffness, incorporation of cell binding cues and inclusion of growth factors. ${ }^{69-71}$

Advances in injectable hydrogels help to solve various clinical challenges in CNS disease treatment. Specifically, injectable hydrogels have received attention as carriers for proteins and drugs. However, initial burst release of loaded proteins and drugs can lead to undesired effects and ineffectiveness of treatment and this has been one of the main challenges for injectable hydrogels. ${ }^{72}$ Many approaches have been developed to overcome this problem. For example, the formation of complex networks via crosslinking to reduce the burst release of incorporated proteins and drugs, ${ }^{73,74}$ "pendant chain" system which delays the release by covalently grafting a protein backbone to the hydrogels via a cleavable linker, ${ }^{75}$ incorporation of proteins and drugs into micro- or nanoparticles to serve as a drug reservoir in the composite hydrogel system, ${ }^{76}$ and incorporation of high-affinity ligands to prolong drug release ${ }^{77}$ have all been reported. Other enhancements in the hydrogel system were also developed to improve the biological effects. In this respect, ligand-functionalization has been extensively studied to enhance cell infiltration and binding capabilities. Small oligopeptide sequences within the ECM proteins such as RGD peptides were incorporated to enhance 

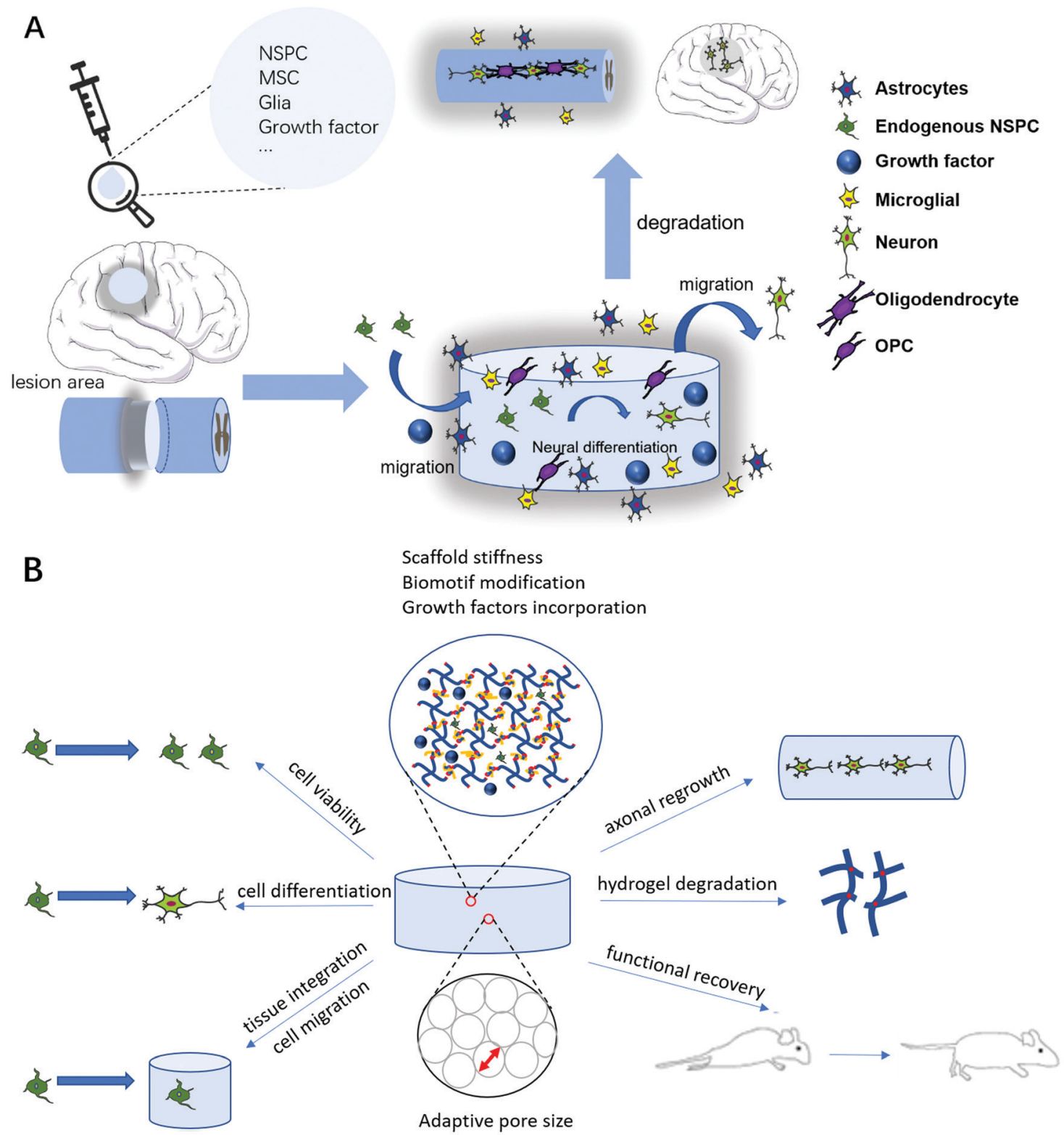

Fig. 1 (A) Administration of injectable hydrogel gelates into the lesion area. The ECM-mimicking network modulates the microenvironment and promotes cell migration and differentiation in the lesion to restore nerve connection. (B) Possible cell behavior considerations of injectable hydrogels.

cell adhesion within the hydrogel. ${ }^{78}$ Furthermore, peptide sequences like IKVAV and YIGSR are known to interact with mammalian neurons. Correspondingly, the incorporation of these sequences has been shown to enhance neural differentiation. ${ }^{79,80}$

\subsection{Incorporation of exogenous cells in injectable hydrogels}

Injectable hydrogels in combination with cell transplantation have been studied extensively in recent years in the hope of improving neural regeneration and functional recovery. Several types of primary cells have been explored. These include neural stem/progenitor cells (NSPCs), Schwann cells (SCs), olfactoryensheathing cells (OECs), mesenchymal stem cells (MSCs) and human-derived induced pluripotent stem cells (iPSCs). ${ }^{20,63,81}$ Among these cell types, NSPCs, MSCs and glial cells are the common cell types to be incorporated within hydrogels for transplantation treatments. In particular, NSPCs can not only differentiate into mature neurons to replace lost cells, but also promote endogenous repair, such as enhancing angiogenesis, providing immunosuppression, and promoting recruitment of endogenous cells. ${ }^{82-84}$ MSCs, on the other hand, play a bigger role in contributing to the stimulation of angiogenesis and inhibition of microglial activation by secreting cytokines (IGF-1, VEGF, EGF and FGF) to reduce neuronal death. MSCs could also potentially differentiate towards the neural lineage. ${ }^{85,86}$ Glial cell transplantation could also be advantageous due to its potential to directly modulate the environment and meditate myelin regeneration. ${ }^{87}$

Despite the efforts from the past decades, there is no effective CNS disease treatment that results in the restoration 
of function. Here, we will look at the recent research studies on injectable hydrogels, including the use of cell transplantation, in the past decade. This ensures that the latest findings on the use of injectable hydrogels are covered. The choices of hydrogel materials will mainly be based on tissue and cellular responses. A brief summary of possible design considerations is shown in Fig. 1B.

\subsection{In vitro cell viability}

Cell transplantation to the CNS often faces the problem of low cell survival rates. In this regard, in vitro cell culture studies focusing on evaluating the roles of hydrogels in the regulation of cellular responses have allowed the close examination of the viability of various cell types when delivered within these biomaterials. In particular, cell-matrix interactions are crucial in modulating cellular homeostasis and directing communication to cell cytoskeleton, growth factor receptors and intracellular signalling cascades to ensure cell survival. ${ }^{88}$ Table 1 summarizes the in vitro studies on cell-incorporated injectable hydrogels and their corresponding cell viability and differentiation outcomes. Previous studies showed that mesenchymal and neural stem cells have the potential to replace lost cells and modulate inflammation and the local wound environment. ${ }^{89}$ Both NSPCs and MSCs seem to be able to survive and proliferate well with proper cellular and physical cues. Most studies have shown that these cells are able to survive in their respective hydrogels for more than 2 weeks, ${ }^{84,85,90-92}$ suggesting sufficient cell-matrix interactions between the incorporated cells and the hydrogel substrates.

Many materials have been tested for cell survival and proliferation in vitro. Among these, we noticed significant improvement in cell proliferation in hyaluronan-, chondroitin sulfateand collagen-based materials. ${ }^{55,71,83,84}$ The findings suggest that natural polymers found abundantly in the body are more suitable for inducing cell proliferation. We believe that the CD44 interaction could be the reason for improvement in cell viability. CD44 is a cell receptor found in various cell types, including neural stem cells and glial cells in the CNS. ${ }^{93-95}$ Specifically, CD44 forms receptor-ligand interactions with natural polymers including $\mathrm{HA}$, chondroitin sulfate and collagen. ${ }^{96-98}$ The activation of the CD44 ligand binding domain allows binding of activator proteins that in turn triggers downstream signalling pathways, such as the Ras-RafMEK-ERK pathway, which leads to cell proliferation. ${ }^{99}$ While studies on cell viability in vivo typically last for 4-8 weeks, Rouleau and colleagues ${ }^{92}$ were able to maintain viable hiPSCderived neurons and glial cells in the silk fibroin hydrogel for more than 2 years. However, given the fact that the silk fibroin hydrogel showed minimal degradation and maintained its hydrogel network over the long culture duration, such materials may be less ideal for the regeneration and replacement by new native tissues. Some studies only conduct in vitro experiments for less than 7 days. ${ }^{100,101}$ It could be beneficial to conduct in vitro experiments for a longer duration to ensure cell survival and the differential potential in vivo, where the environment is harsher.

\subsection{In vitro cell differentiation}

Cell transplantation can modulate the diseased microenvironment by enhancing cell differentiation. Cell differentiation is crucial for the transplanted stem and progenitor cells to differentiate into mature and functional cells. This allows replacement of diseased tissues, promotes tissue regeneration through the secretion of regenerative factors and provides neuroprotection. ${ }^{102,103}$ While the effectiveness of cell transplantation depends largely on the number of cells transplanted, undifferentiated cells were shown to minimize cell death as compared to fully differentiated transplanted cells. ${ }^{104}$ Previous work done by Payne and colleagues ${ }^{82}$ showed that the transplantation of undifferentiated induced pluripotent stem cellderived neural stem cells (iPSC-NSCs) resulted in greater functional repairs compared to late-differentiated cells which caused more tissue damage due to greater cell death.

From Table 1, some of the studies demonstrated the ability of injectable hydrogels to promote encapsulated cell differentiation to express immature neuronal markers at short time points ${ }^{105,106}$ and mature neural markers at longer time points. ${ }^{90,98}$ The choice of hydrogel materials seems to be critical in promoting the differentiation of encapsulated cells. SAPs are able to facilitate the differentiation of cells to express mature neuronal or oligodendrocyte markers without further modification of materials. ${ }^{90,98}$ Natural materials, on the other hand, often rely on additional modification to enhance cell differentiation in vitro. For example, hyaluronic acidmethylcellulose (HA-MC) alone did not enhance the differentiation of NSPCs as compared to cells cultured in neurobasal media. ${ }^{105}$ Collagen-only hydrogels worsened the differentiation potential of NSCs to neuronal lineage as compared to cells cultured on poly-D-lysine (PDL)-coated coverslips. ${ }^{107}$ In vitro cell differentiation was enhanced when these natural polymers were further modified with bioactive motifs (e.g. IKVAV, LRE peptides) or incorporation of growth factors (e.g. PDGF, VEGF). ${ }^{108-111}$ We believe that, while injectable hydrogels made of natural materials are better in promoting cell viability in vitro, cell differentiation could be attributed to the presence of bioactive peptide sequences. SAPs are shown to have greater potential in promoting differentiation as they can be readily modified to include bioactive peptide sequences. Natural polymers, however, also achieved improved differentiation outcomes after biomotif modification. Specifically, Silva and colleagues $^{112}$ compared the differentiation outcomes between scaffolds containing the bioactive IKVAV sequence, a nonbioactive sequence and a cell suspension with IKVAV soluble peptide. The results demonstrated that physical entrapment of bioactive epitope SAPs was the main reason for improvement in cell differentiation. Moreover, the stiffness of the hydrogels influences not only cell survival, but also the differentiation fate of transplanted cells. ${ }^{113}$ For example, silk is a stiff material by nature, ${ }^{83}$ thus affecting the differentiation potential of encapsulated neural stem cells. Although there are conflicting reports on cell differentiation potential in silk fibroin hydrogels in vitro, ${ }^{92,114}$ the high intrinsic stiffness of silk could explain the inconsistency in different studies and the low percentage of 


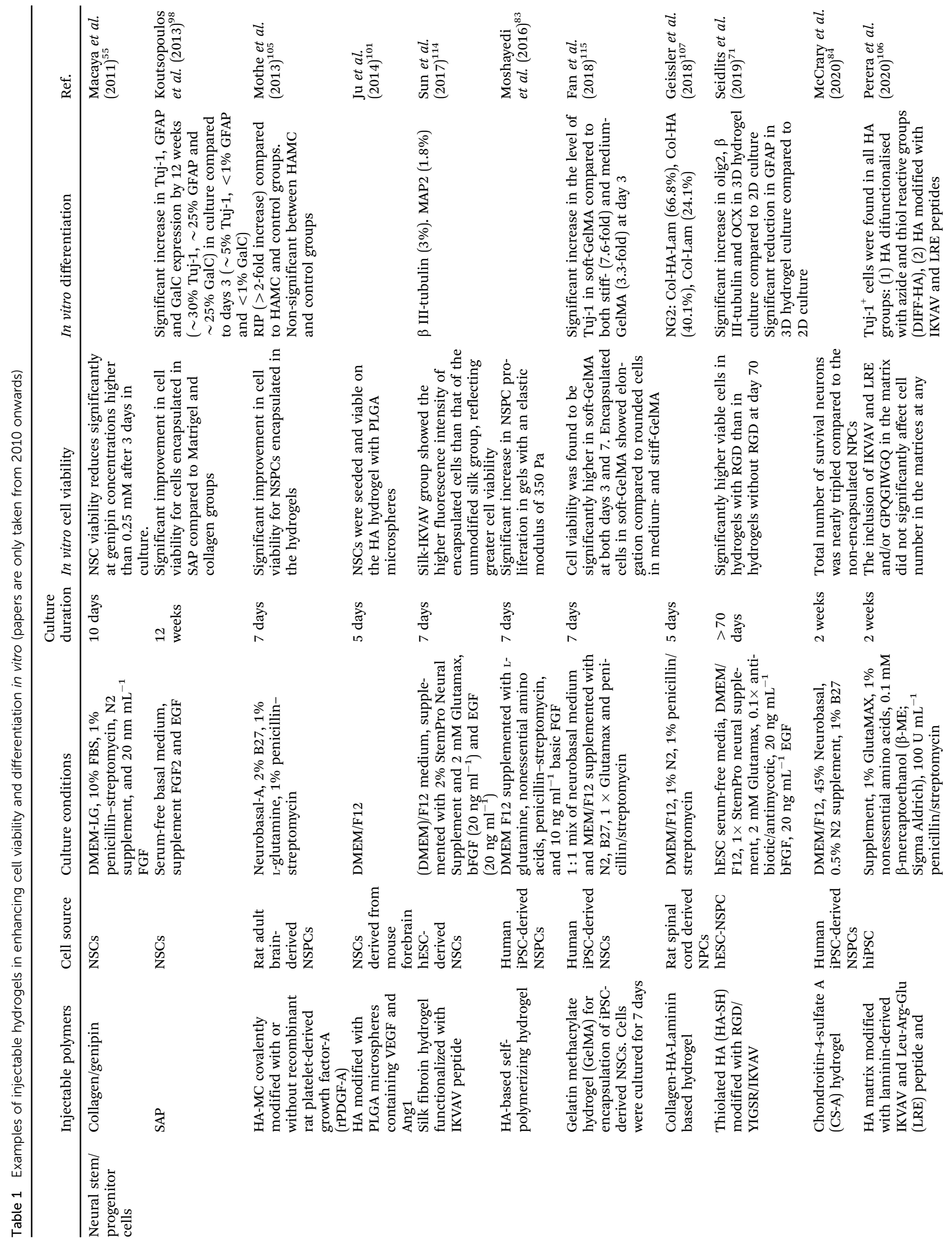




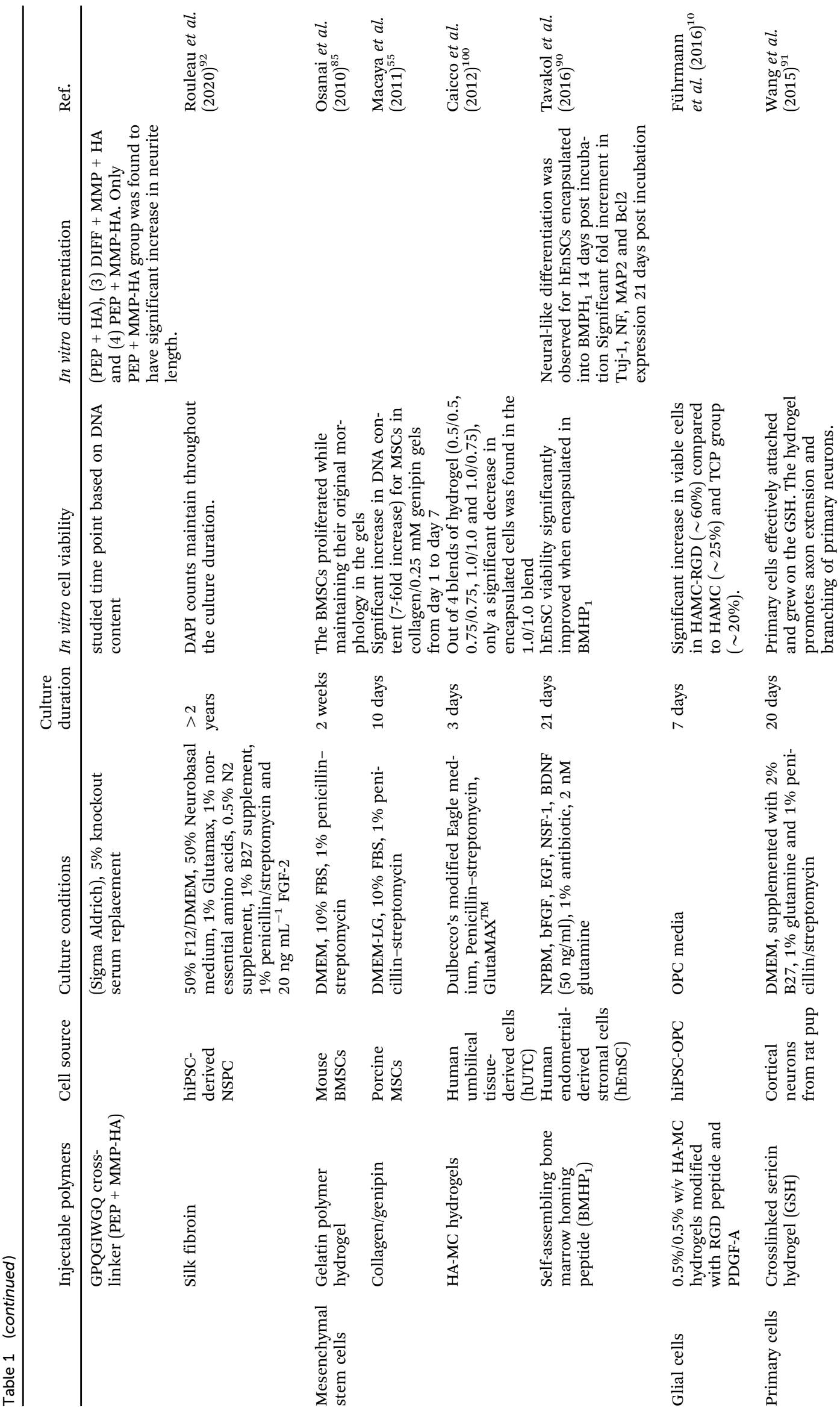


neural differentiation observed by Sun and colleagues. On the other hand, Fan and colleagues ${ }^{115}$ tested gelatin methacrylate hydrogels (GelMA) of different stiffnesses using a compression test. Specifically, three different stiffnesses of hydrogels were tested, including soft $(\sim 680 \mathrm{~Pa})$, medium $(\sim 1230 \mathrm{~Pa})$ and hard $(\sim 2030 \mathrm{~Pa})$, and the group concluded significant improvements in both in vitro cell viability and differentiation with soft-GelMA gels. The measured stiffness of the soft hydrogel matches the stiffness of the CNS tissues, ${ }^{52}$ which explains the findings from the study.

\subsection{In vivo tissue integration and cell migration}

Tissue integration can be defined as the physical, biological and mechanical connection of the interface between the implanted materials and the surrounding native tissues. ${ }^{116}$ Poor tissue integration of the scaffold is often one of the factors contributing to poor cell survival and tissue regeneration in vivo. It often leads to the formation of fibrous scarring and cystic cavity which obstructs potential neuronal ingrowth. ${ }^{64,117}$ Proper integration between the tissue and scaffold often results in a high degree of cell infiltration to modulate the microenvironment in the lesion, given that the architectures of the scaffold are permissive to cell infiltration. ${ }^{118}$ In addition, tissue integration is also related to supporting axonal growth by facilitating endogenous cell infiltration and migration and deposition of laminin. ${ }^{119}$ Endothelial cell infiltration and the formation of blood vessels as blood flow are also essential to sustain the growth of regenerating axons and the surrounding tissues. $^{84}$

In the local inhibitory microenvironment of the CNS, differentiation of transplanted stem cells into neurons for long-term survival and tissue integration is particularly challenging. As shown in Table 2, scaffolds that exhibit good tissue integration and promote cell migration typically result in reduced presence of reactive astrocytes $\left(\mathrm{GFAP}^{+}\right)$and inflammatory cells $\left(\right.$ IBA- $\left.1^{+}\right)$. Further examination also confirms the ability of neurons to infiltrate into the hydrogel $\left(\mathrm{NF}^{+}, \mathrm{NeuN}^{+}, \mathrm{DCX}^{+}\right.$, Tuj- $1^{+}, \beta$ III Tubulin ${ }^{+}$, etc.). We believe that these injectable hydrogels do provide sufficient tissue integration as evident from the reduced inflammation and enhanced cell migration and differentiation.

Overall, there seems to be no distinctively "perfect" material that promotes tissue integration and cell migration. In fact, many studies have shown evidence of improvement in scaffoldtissue connection and cell infiltration regardless of the choice of materials. Improvement in tissue-scaffold integration can be indicated by (1) a reduction in tissue scarring, ${ }^{101,120,121}$ (2) a reduction in cystic cavity, ${ }^{119,122}$ and (3) infiltration of endothelial cells. ${ }^{84,123,124}$ While natural polymers and ECM-mimicking SAPs can be modified to improve implant integration into native tissues, it is worthwhile to note that other than ensuring good integration to the tissues surrounding the lesion, the pore size of the scaffold should also be carefully considered to ensure that the internal architecture of the hydrogel is conducive to cell infiltration. ${ }^{5}$ Furthermore, while scaffolds are usually made of hydrophilic materials or coupled with hydrophilic antigens to improve tissue and cell attachment, the stiffness of the scaffold is also an important parameter to consider for proper tissue integration and promoting cell migration. As studied by Lam and colleagues, ${ }^{9}$ HA hydrogels with two different stiffnesses were examined and significantly higher $\mathrm{GFAP}^{+}$signals were found in the animals that were implanted with the stiffer scaffold. This potentially leads to larger cystic cavity and reduced cell migration.

\subsection{In vivo axonal regrowth}

One of the main objectives in CNS therapy is to promote axonal regrowth and to reconnect neuronal network. Axonal regeneration is one important factor influencing tissue recovery by sprouting uninjured axons and eventually leading to functional recovery. ${ }^{125}$ The use of injectable hydrogels could enhance axon regeneration from the corticospinal tract (CST). ${ }^{6}$ Cell transplantation also facilitates the regeneration by either the differentiation of exogenous transplanted cells ${ }^{9}$ or facilitating the differentiation of endogenous neurons. ${ }^{13}$ Since injured axons in the CNS do not actively regenerate, the amount and extent of axonal regrowth within the scaffold are important parameters to be considered for potential functional recovery. From Table 2, most groups deployed the strategy of attracting the migration of endogenous NSPCs into the lesion and promoting their proliferation and differentiation into neurons. Although neuron markers like DCX and Tuj-1 could sufficiently prove the capability of these hydrogels in promoting neurallike proliferation and differentiation, most studies do not provide evidence of mature neuron differentiation. On the other hand, mature neuron markers (MAP2, NeuN, NF, etc.) could be better choices as indicators of growing mature neurons that are associated with axonal sprouting. ${ }^{126}$ This is because axonal sprouting is known for strengthening existing connections and facilitating new synaptic connection across the lesion, which are essential to restore proper signal transmission. ${ }^{127}$

While most growth factor-incorporated scaffolds seemed to be more effective in promoting axonal regrowth and tissue regeneration, we identify three materials with significant improvement in axon regeneration marked by the expression of mature neuron markers: SAP ${ }^{128} \mathrm{HA}^{-\mathrm{MC}^{10,129}}$ and heparinpoloxamer (HP). ${ }^{130}$ The SAP was made of laminin-derived IKVAV, ${ }^{128}$ HA-MC, was modified with the RGD sequence and growth factors were incorporated in both HA-MC and HP hydrogels. ${ }^{10,130}$ These modifications facilitated attachment and promoted the proliferation of cells to modulate the microenvironment that is conducive to axonal regrowth. The incorporation of OPCs in the hydrogel also potentiates the differentiation into oligodendrocytes. ${ }^{10}$ We believe that these materials, with proper modifications that facilitate cell infiltration and differentiation, could effectively promote axonal regeneration and preserve the integrity of newly formed axons. In addition, BDA labelling done by Liu's group ${ }^{120}$ (SAP hydrogel) and Wang's group ${ }^{130}$ (HP hydrogel) confirmed the connection of neurons between newly formed axons and those in native tissues, which could potentiate functional recovery. 


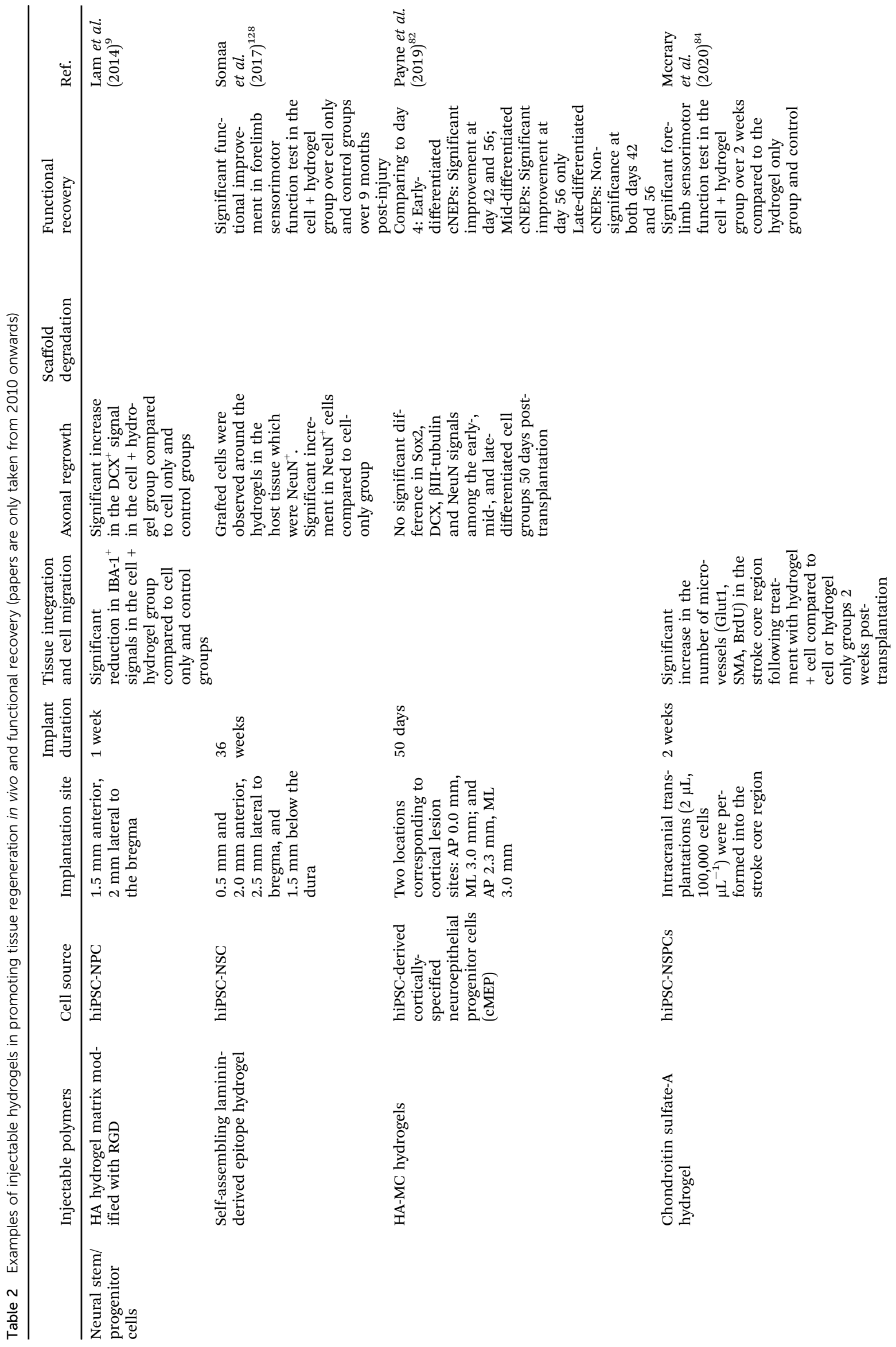




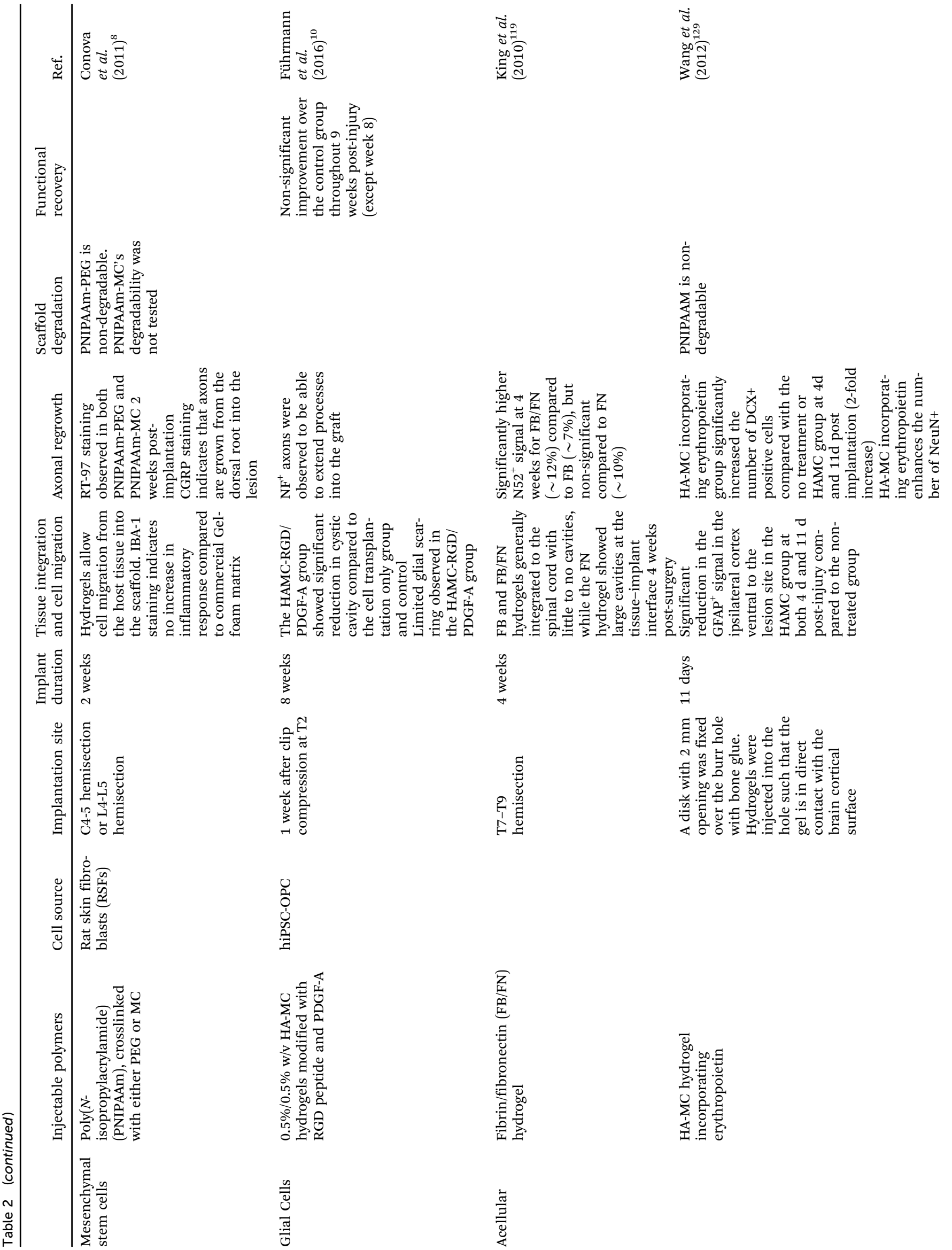




\begin{tabular}{|c|c|}
\hline$\approx$ & 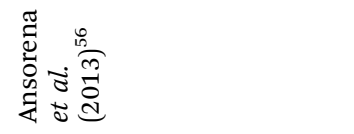 \\
\hline 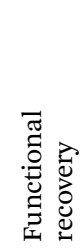 & 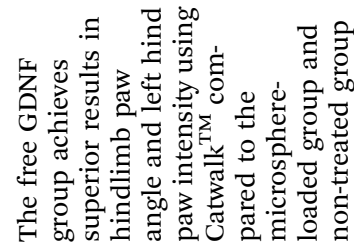 \\
\hline
\end{tabular}

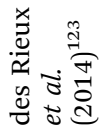

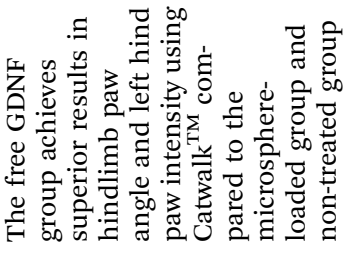

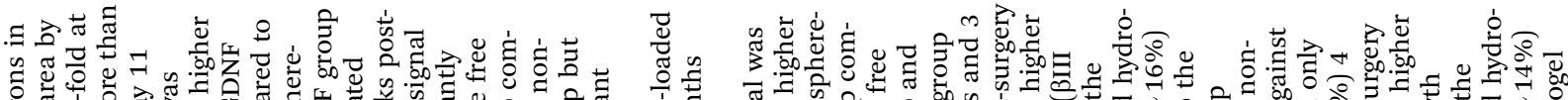

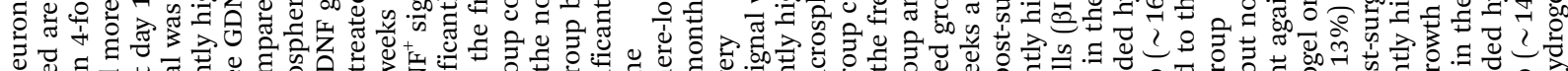

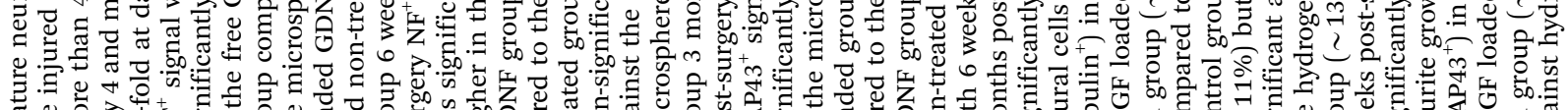

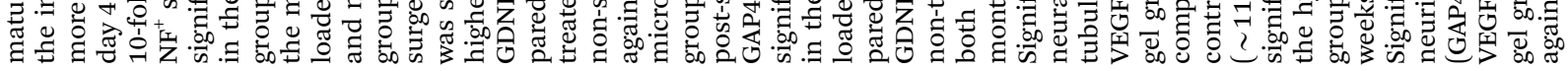

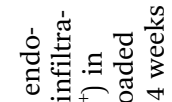

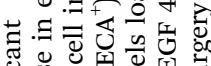

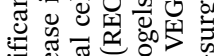

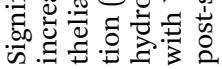

$\approx \frac{\mathscr{n}}{\varpi}$

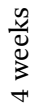

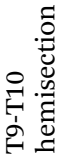

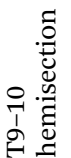

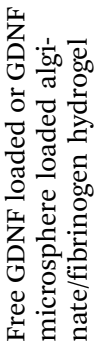

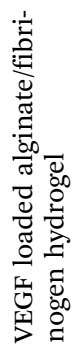




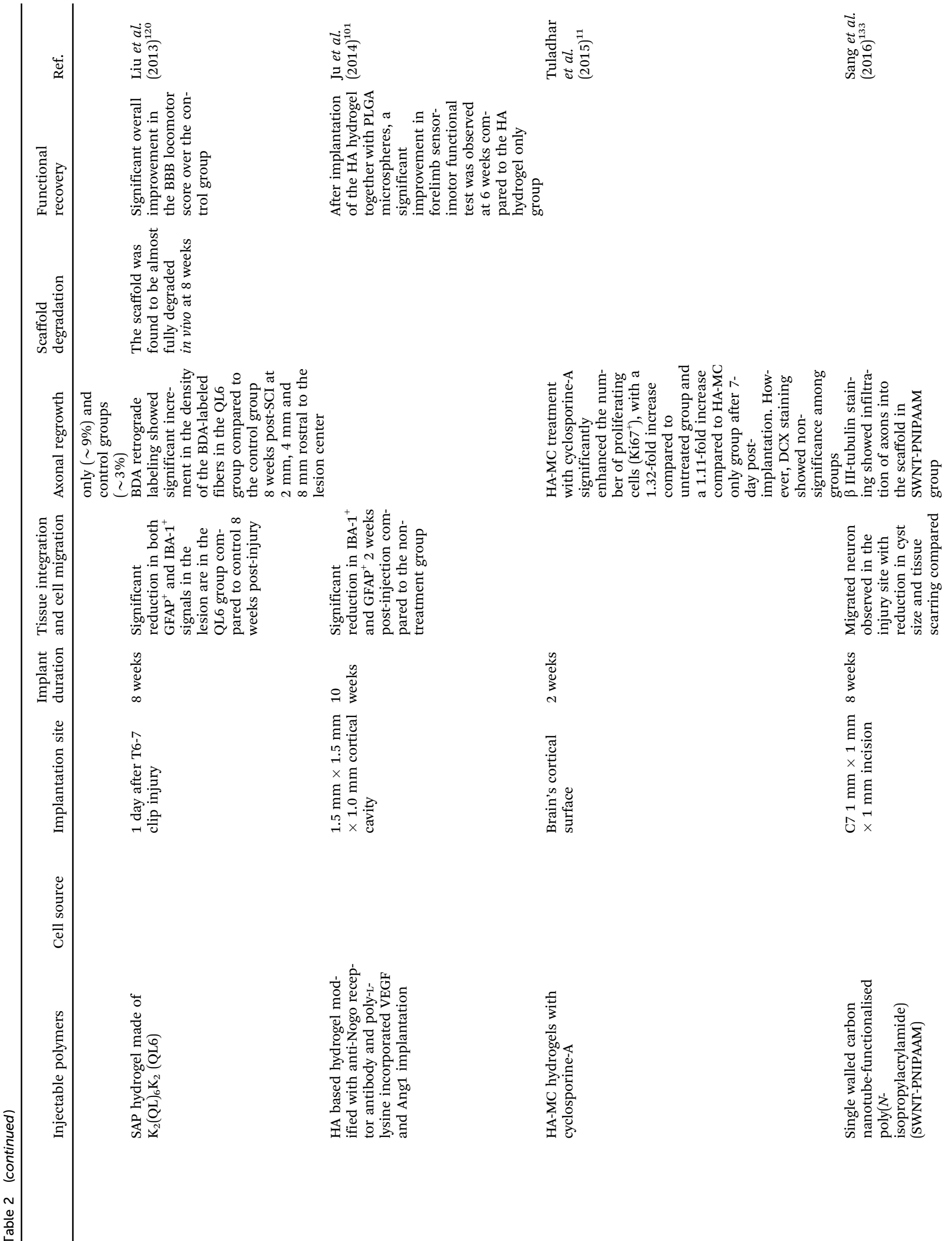


ปี่

旅客

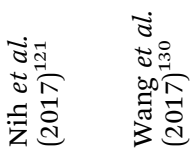

苑

苞芯苍

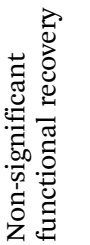

$\Xi \stackrel{5}{\pi}$

节苛

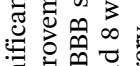

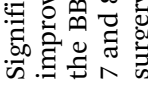

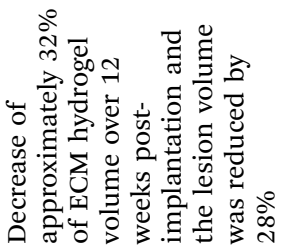

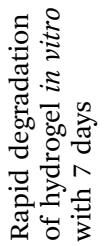

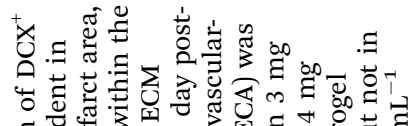

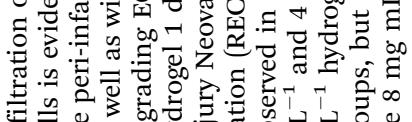

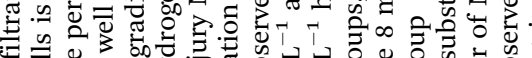

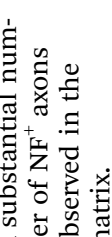

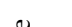

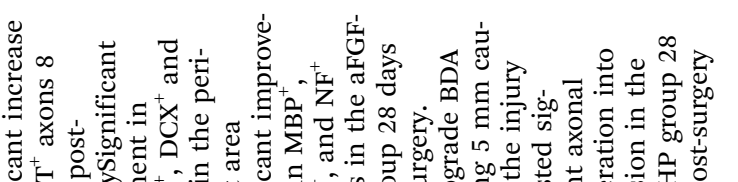

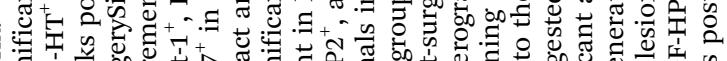
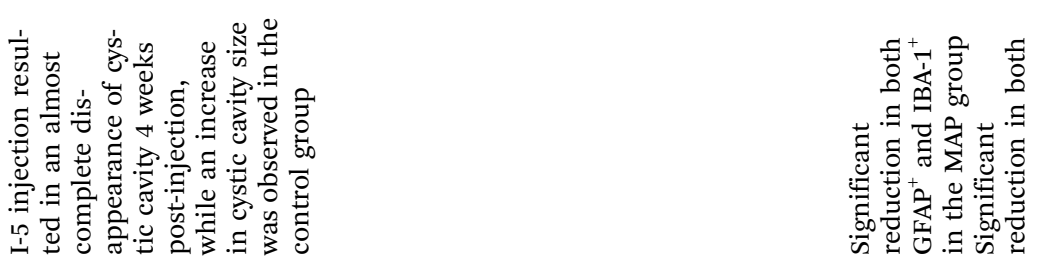

$\approx \stackrel{\mathscr{\Xi}}{\frac{\mathscr{J}}{3}}$

$n$
$\frac{n}{2}$
$\vdots$
$\infty$

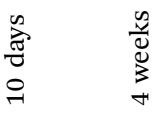

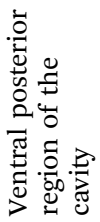

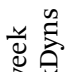

$\rightarrow \frac{1}{1} \cdot \frac{1}{8}$

官㤩

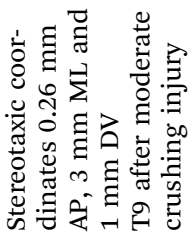

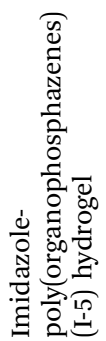

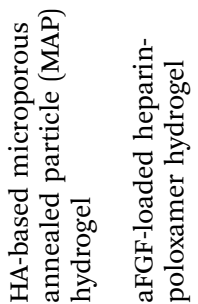




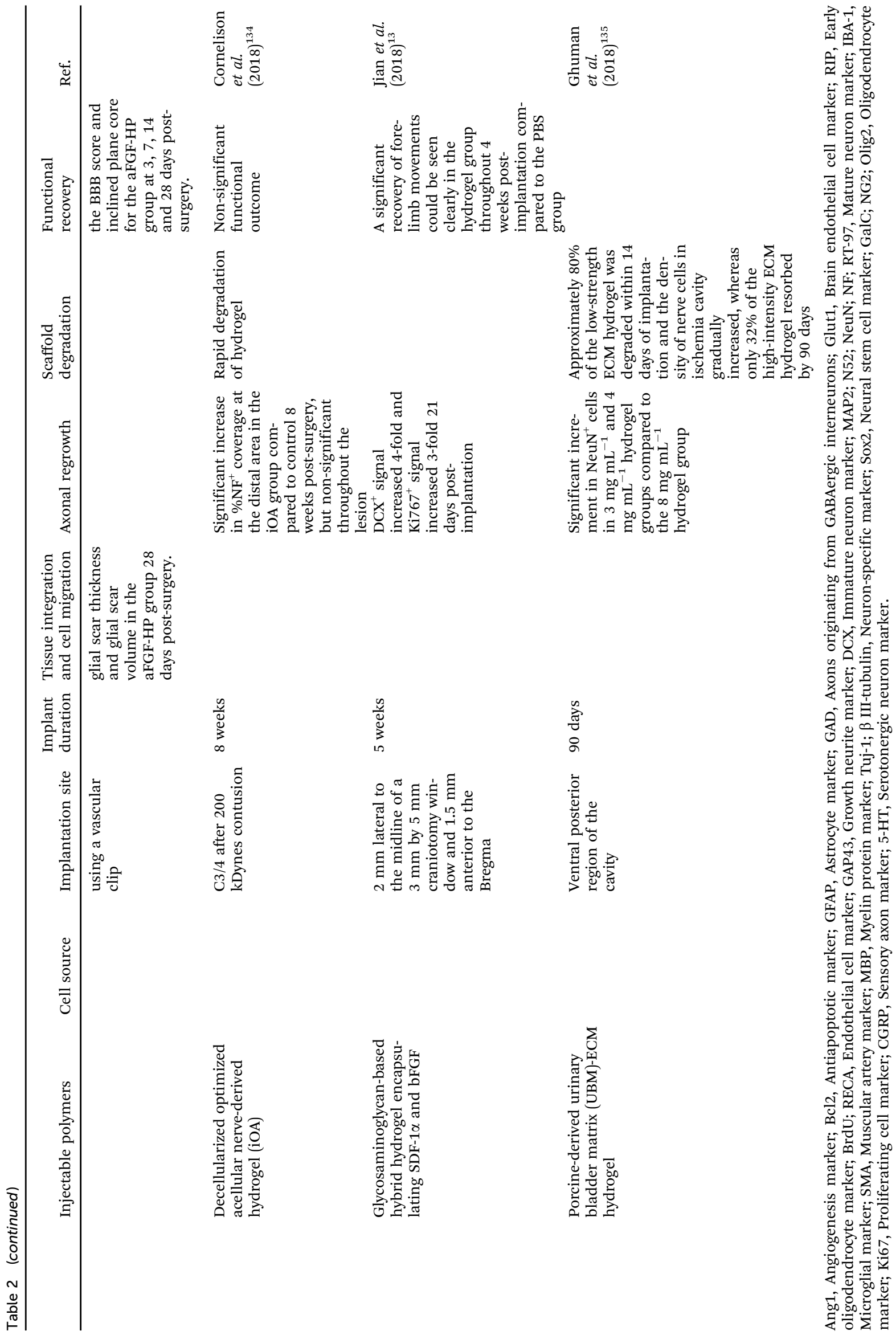




\subsection{Scaffold degradation}

The degradation rate of an injectable scaffold plays an important role in tissue regeneration. Fast scaffold degradation potentially leads to implant failure as the void space suppresses the formation of mechanically competent tissues to support the growth and development of newly formed cells and tissues. ${ }^{131,132}$ In contrast, slow scaffold degradation impedes the growth of new axons and tissues. ${ }^{6}$ With the implantation time being prolonged, an excessively large volume of hydrogel will reduce the invasion of migrating cells and the potential recovery could be sub-optimal. One important consideration for hydrogel degradation is to anticipate the rate of degradation with respect to axonal regrowth.

From Table 2, the non-degradable poly $(N$-isopropylacrylamide) (PNIPAAm) scaffold could provide permanent support for regeneration, ${ }^{8,133}$ but it could potentially prevent tissue regrowth. On the other hand, the rapid degradation of the decellularized optimized acellular nerve-derived hydrogel $(\mathrm{iOA})^{134}$ resulted in thick and dense GFAP at the scaffold-tissue interface. We believe that the lack of overall neurite ingrowth and functional recovery could be due to insufficient early mechanical support. In the early stage of hydrogel scaffold implantation, there will be continuous cell migration, including macrophages, NSPCs, astrocytes and OPC, where the migration of macrophages accelerates the biodegradation of the scaffold. ${ }^{135}$ Loss of mechanical support leads to failure in the cell-ECM interaction and the following signal transduction to promote cell development and growth, hence the decline in the potential regrowth of native tissues to serve as the structural support to continue assisting in cell and tissue regeneration. In this regard, Cornelison et al. ${ }^{134}$ suggested a duration that is required for the onset of axon regeneration, which is typically between 4 and 6 weeks post-injury. However, we observed robust NF infiltration into fiber-hydrogel scaffolds as early as one week post-injury. ${ }^{136}$ Significant improvement in axonal regrowth was also found in other studies with the hydrogel degradation rate being faster than this proposed period. ${ }^{122,135}$ These observations could be attributed to the hydrogel materials that were used and the corresponding affinity of cells towards these materials, which in turn facilitated cell-matrix interactions to promote tissue regrowth. Along this line, studies have also shown that hydrogel degradation plays a significant role in influencing cell behavior and differentiation. ${ }^{137}$ For example, MSC spreading and survival have been shown to be directly correlated to the hydrogel degradation rate. ${ }^{138}$ Therefore, the degradation rate of hydrogels should be tailored to the hydrogel materials used and controlled to promote cell survival and differentiation behavior.

\subsection{Functional recovery}

One of the ultimate goals of CNS treatment is to restore both sensory and motor functional capabilities. Axonal regeneration has been shown to be closely related to functional recovery in CNS diseases. Angiogenesis and recruitment of cells for neurogenesis to the injured areas are equally crucial. ${ }^{1,83,139,140}$
While axonal regrowth into the lesion is encouraging, functional recovery requires reconnection of neurons between rostral and caudal sides. ${ }^{123}$ From Table 2, the discoveries from various research groups seem to suggest that significant axonal regrowth does not always equate to functional recovery. For example, HA-based hydrogels were observed to promote axonal regrowth in the previous sections. ${ }^{10,129}$ However, not all studies showed the expected functional recovery. One possible reason could be the differentiation nature of transplanted cells. Führmann et al. ${ }^{10}$ suggested that only a portion of transplanted cells would differentiate into mature and functional oligodendrocytes and myelinated axons. Payne et al. ${ }^{82}$ compared the differentiation stages of NSPCs in transplantation and found out that late-differentiated cells were less effective in promoting functional recovery. Perhaps the maturity of transplanted cells should also be an important consideration, given that matured cells are more sensitive to the injection transplantation process. In addition, the type of transplanted cell also plays a role in either supporting the growth of endogenous tissues or integrating with the host tissues. ${ }^{141}$ Embryonic stem cells (ESCs) are known to be capable of differentiating into nearly all cell phenotypes. Advances in genetic modification allow directed differentiation of ESCs to the desired cell types, such as neurons and oligodendrocytes for CNS repair. ${ }^{142}$ MSCs are used in cell transplantation in the CNS for both neuroprotection and neuroregeneration strategies, where cells are used to either protect parenchymal cells in the lesion or promote axonal regeneration and sprouting. MSCs are able to secrete pro-survival growth factors (e.g. BDNF, VEGF, FGF2, etc.) and have the potential to be differentiated into neurons. ${ }^{143}$ The use of iPSCs has gained popularity in recent years due to the ability to reprogram to xeno-free and genetically stable cells to potentiate recovery in the CNS such as neuroprotection, modulation and regeneration. The ability to be derived into different neural lineages, for example, neural network reconstruction by iPSC-derived neural cells, axon remyelination by oligodendrocytes, and neurotrophic factors secreted by neural cells, shows promising therapeutic effects for cell transplantation. ${ }^{144}$

As a result of CNS injury, trophic factors are downregulated. ${ }^{145}$ Many groups have incorporated growth and trophic factors into hydrogels to help stimulate neural regeneration and growth. Both Ansorena et al. ${ }^{56}$ and des Rieux et al. ${ }^{123}$ studied growth factor-loaded alginate/fibrinogen hydrogels, but the latter were unable to achieve improved functional recovery. This could be due to the insufficient amount of growth factors incorporated into the hydrogels to support axonal growth. Lutton et al. ${ }^{146}$ also suggested that the sole effect of VEGF might not be sufficient for modulating regeneration in the complex CNS environment and would require a combination of effects from other growth or trophic factors. Scaffolds that promoted decent animal behaviour outcomes typically had a degradation rate of no less than 4 weeks and were almost fully degraded at about 8 weeks post-injury. The fast rate of hydrogel degradation might be a possible reason for poor functional recovery in some studies as fast degradation of hydrogels failed to provide sufficient support for growing axons. $^{134}$ 
There are many factors contributing to functional recovery after CNS injuries. Although studies show conflicting findings on the correlation between axonal regeneration and functional recovery, reconnection of the neural network is still important as neural signal conduction is crucial for recovery of movements. Axonal regeneration is affected by the hydrogel material used, the maturity and types of transplanted cells, the involvement of hydrogel modification and growth factors, and hydrogel degradation. Recent studies have also focused on the involvement of glial cells in axonal regeneration and functional recovery. For example, studies have suggested that astrocyte recruitment to the lesion site may have a permissive role in axonal growth instead of only forming an inhibitory barrier ${ }^{147,148}$ and demonstrated the ability for inflammation regulation and minimizing cellular degeneration. ${ }^{149,150} \mathrm{OPC}$ proliferation, oligodendrocyte differentiation and maturation are also important to promote axonal remyelination. ${ }^{151}$

\section{Summary and suggestions for future works}

The treatments for CNS diseases are limited. The prognosis of patients is often poor and this could seriously reduce their quality of life. Stem cell transplantation has registered several clinical studies by protecting and repairing CNS injuries. The transplanted stem cells can aid in repairing damaged nerves and also play a beneficial role through immune regulation or regulation of endogenous regeneration. However, cell transplantation faces minimal success at clinical stage mainly to due poor survivability and poor tissue integration of transplanted cells. $^{17}$

From the studies in the recent years, HA-based hydrogels seem to be more popular options in CNS disease treatments. Since the first report of the study involving HA coupled with methyl cellulose, ${ }^{152}$ hyaluronan-based hydrogels have been widely used in the animal models for the treatments of CNS diseases owing to its injectability and thermoresponsiveness. HA also helps to attenuate inflammatory response and promote endogenous axonal regrowth in the body. ${ }^{11}$ Nevertheless, regardless of hydrogel materials, recent CNS disease treatments seem to be focusing on eliciting endogenous neurogenesis, probably due to the concerns in immune response due to exogenous cell transplantation and the possibility of teratoma formation. Although exogeneous cell incorporation in injectable hydrogels has become an increasingly popular option, many studies only focused on the potential and differentiation outcomes of cell encapsulation within injectable hydrogels in vitro, but did not proceed with cell transplantation in vivo and only focused on the effects of acellular hydrogels and encapsulated molecules on tissue regeneration. It is difficult to determine the best scaffold material with the most effective therapeutic outcomes. For example, certain materials are more effective in promoting cell survival (e.g. natural materials) and certain materials promote cell differentiation (e.g. SAPs). ECM modifications and biomolecule incorporation are also effective in enhancing the therapeutic effects of injectable hydrogels. The choice of hydrogel materials could, therefore, be based on the desired outcome of the studies. We are hopeful that the information provided in this review could offer insights that would be useful for the future design of injectable hydrogels.

To ensure that research on injectable hydrogels is clinically relevant, functional recovery should be the focus of the studies. This is because the end goal for any treatment options is to improve and restore the functional capabilities of patients. ${ }^{153}$ The CNS functions are so diverse and complex that it is not possible to only use a single assessment method to cover all aspects of functions. This includes sensory, locomotor, and cognitive functions such as learning, memory and problem solving. ${ }^{154}$ Sensory recovery and feedback are important in controlling motor functions, while motor recovery is responsible for initiating muscle fibers to achieve limb movements. ${ }^{155}$ Common sensory tests include Von Frey Hair (VFH) microfilament tactile sensory test ${ }^{156}$ and heat and cold sensation tests. ${ }^{157,158}$ Locomotor tests, on the other hand, include Basso, Beattie and Bresnahan (BBB) scale, ${ }^{159}$ open field tests ${ }^{160-163}$ and swim tests. ${ }^{164}$ As symptoms of anxiety are common poststroke and SCI, open field tests that make use of rodents' behavior to stay at the corners under stress or anxiety are also commonly used. ${ }^{155,165}$ Cognition assessment is crucial for neurological functions including memory and emotions. This is especially critical after stroke as patients often suffer from cognitive impairments. ${ }^{166}$ Some common methods to assess memory in animals include Morris water maze test (Morris, 1981) ${ }^{167}$ Y-maze test ${ }^{168}$ novel object recognition/location test $^{169}$ and radial-arm test. ${ }^{170}$ The key for choosing the appropriate functional assessment scale should depend on the surgical models used and knowing the advantages and limitations of different systems to choose the most appropriate assessment methods.

Instead of discovering new material combinations for CNS disease treatment, the focus of future research may shift more from the development of new materials to understanding the mechanisms behind the tissue response towards the hydrogels and axon reconnection leading to functional recovery after hydrogel implantation. While animal models are essential to examine the effectiveness of injectable hydrogels in vivo, alternatives, such as ex vivo or organ-on-a-chip models, may be useful platforms to assess the effectiveness of hydrogel materials. Ex vivo models, organotypic slice culture (OSC), for example, can serve as alternatives to assess the post-injury interaction of cells within the spinal cord. OSC is able to mimic the post-injury environment by recapitulating elements of glial scar. This could be useful in tackling the issues of glial scarring in spinal cord repair. ${ }^{171}$ Neural system-on-a-chip is a scaffoldbased in vitro system for studies of complex physiological tissue interactions on a functional and customizable substrate. The system may be useful as a platform to study the nerve injury model since it allows direct observation of the states of injury and regeneration. It also potentially allows the studies of higher order neural anatomies. ${ }^{172}$ With these platforms, we could possibly achieve direct observation of cellular response towards 
various scaffold materials within a shorter period of time and with reproducibility. This could ease the efforts of testing scaffolds in vivo and cut down on the costs of animal studies. The limitations of these platforms could be the inability to assess inflammatory response and interaction between the immune system and the injury lesion. Additionally, functional studies can only be carried out with in vivo models.

Despite some limitations in current studies on in situ injectable hydrogels, some groups have managed to obtain promising axonal recovery and functional improvement. This provides incentives for continuing the development of injectable hydrogels in CNS injury treatment. With increasing understanding on the physiologies of CNS, there is hope that we can engineer optimal injectable hydrogels that are useful and beneficial to clinical applications.

\section{Conflicts of interest}

The authors declare no conflict of interest.

\section{Acknowledgements}

This work was supported by the National Research Foundation, Singapore, under its Intra-CREATE Thematic Grant Programme (NRF2019-THE002-0001) and the MOE Tier 1 grants (RG38/19 and RG37/20).

\section{Notes and references}

1 A. Gopalakrishnan, S. A. Shankarappa and G. K. Rajanikant, Hydrogel scaffolds: Towards restitution of ischemic strokeinjured brain, Transl. Stroke Res., 2019, 10(1), 1-18.

2 S. H. Koh and H. H. Park, Neurogenesis in stroke recovery, Transl. Stroke Res., 2017, 8(1), 3-13.

3 A. S. Go, D. Mozaffarian, V. L. Roger, E. J. Benjamin, J. D. Berry and W. B. Borden, et al., Heart disease and stroke statistics - 2013 update: A report from the American Heart Association, Circulation, 2013, 127(1), e6-e245.

4 J. H. Badhiwala, C. S. Ahuja and M. G. Fehlings, Time is spine: A review of translational advances in spinal cord injury, J. Neurosurg., 2018, 30(1), 1-18.

5 D. Macaya and M. Spector, Injectable hydrogel materials for spinal cord regeneration: A review, Biomed. Mater., 2012, 7(1), 012001.

6 P. I. Morgado, M. Palacios and J. Larrain, In situ injectable hydrogels for spinal cord regeneration: advances from the last 10 years, Biomed. Phys. Eng. Exp., 2019, 6, 1.

7 Z. Yu, H. Li, P. Xia, W. Kong, Y. Chang and C. Fu, et al., Application of fibrin-based hydrogels for nerve protection and regeneration after spinal cord injury, J. Biol. Eng., 2020, 14, 22.

8 L. Conova, J. Vernengo, Y. Jin, B. T. Himes, B. Neuhuber and I. Fischer, et al., A pilot study of $\operatorname{poly}(N$-isopropylacrylamide)- $g$-polyethylene glycol and poly( $N$-isopropylacrylamide)-g-methylcellulose branched copolymers as injectable scaffolds for local delivery of neurotrophins and cellular transplants into the injured spinal cord, J. Neurosurg., 2011, 15(6), 594-604.

9 J. Lam, W. E. Lowry, S. T. Carmichael and T. Segura, Delivery of iPS-NPCs to the stroke cavity within a hyaluronic acid matrix promotes the differentiation of transplanted cells, Adv. Funct. Mater., 2014, 24(44), 7053-7062.

10 T. Fuhrmann, R. Y. Tam, B. Ballarin, B. Coles, I. Elliott Donaghue and D. van der Kooy, et al., Injectable hydrogel promotes early survival of induced pluripotent stem cellderived oligodendrocytes and attenuates longterm teratoma formation in a spinal cord injury model, Biomaterials, 2016, 83, 23-36.

11 A. Tuladhar, C. M. Morshead and M. S. Shoichet, Circumventing the blood-brain barrier: Local delivery of cyclosporin A stimulates stem cells in stroke-injured rat brain, J. Controlled Release, 2015, 215, 1-11.

12 J. M. Obermeyer, A. Tuladhar, S. L. Payne, E. Ho, C. M. Morshead and M. S. Shoichet, Local delivery of brainderived neurotrophic factor enables behavioral recovery and tissue repair in stroke-injured rats, Tissue Eng., Part A, 2019, 25(15-16), 1175-1187.

13 W. H. Jian, H. C. Wang, C. H. Kuan, M. H. Chen, H. C. Wu and J. S. Sun, et al., Glycosaminoglycan-based hybrid hydrogel encapsulated with polyelectrolyte complex nanoparticles for endogenous stem cell regulation in central nervous system regeneration, Biomaterials, 2018, 174, 17-30.

14 L. Fernandez-Garcia, J. Perez-Rigueiro, R. MartinezMurillo, F. Panetsos, M. Ramos and G. V. Guinea, et al., Cortical reshaping and functional recovery induced by silk fibroin hydrogels-encapsulated stem cells implanted in stroke animals, Front. Cell. Neurosci., 2018, 12, 296.

15 M. J. Cooke, Y. Wang, C. M. Morshead and M. S. Shoichet, Controlled epi-cortical delivery of epidermal growth factor for the stimulation of endogenous neural stem cell proliferation in stroke-injured brain, Biomaterials, 2011, 32(24), 5688-5697.

16 K. S. Straley, C. P. F. Wong and S. C. Heilshorn, Biomaterial design strategies for the treatment of spinal cord injuries, J. Neurotrauma, 2010, 27, 1-19.

17 T. C. Lim and M. Spector, Biomaterials for Enhancing CNS Repair, Transl. Stroke Res., 2017, 8(1), 57-64.

18 V. A. Kornev, E. A. Grebenik, A. B. Solovieva, R. I. Dmitriev and P. S. Timashev, Hydrogel-assisted neuroregeneration approaches towards brain injury therapy: A state-of-the-art review, Comput. Struct. Biotechnol. J., 2018, 16, 488-502.

19 B. Niemczyk, P. Sajkiewicz and D. Kolbuk, Injectable hydrogels as novel materials for central nervous system regeneration, J. Neural Eng., 2018, 15(5), 051002.

20 M. Modo, Bioscaffold-induced brain tissue regeneration, Front. Neurosci., 2019, 13, 1156.

21 V. Feigin, B. Norrving, C. L. M. Sudlow and R. L. Sacco, Updated criteria for population-based stroke and transient ischemic attack incidence studies for the 21st century, Stroke, 2018, 49(9), 2248-2255.

22 C. L. Gooch, E. Pracht and A. R. Borenstein, The burden of neurological disease in the United States: A summary report and call to action, Ann. Neurol., 2017, 81(4), 479-484. 
23 A. Alizadeh, S. M. Dyck and S. Karimi-Abdolrezaee, Traumatic spinal cord injury: An overview of pathophysiology, models and acute injury mechanisms, Front Neurol., 2019, 10, 282.

24 H. S. Sekhon and M. G. Fehlings, Epidemiology, demographics, and pathophysiology of acute spinal cord injury, Spine, 2001, 26, S2-S12.

25 C. H. Tator and M. G. Fehlings, Review of the secondary injury theory of acute spinal cord trauma with emphasis on vascular mechanisms, J. Neurosurg., 1991, 75, 15-26.

26 C. Profyris, S. S. Cheema, D. Zang, M. F. Azari, K. Boyle and S. Petratos, Degenerative and regenerative mechanisms governing spinal cord injury, Neurobiol. Dis., 2004, 15(3), 415-436.

27 J. W. Fawcett, The extracellular matrix in plasticity and regeneration after CNS injury and neurodegenerative disease, Prog. Brain Res., 2015, 218, 213-226.

28 N. Hlavac, M. Kasper and C. E. Schmidt, Progress toward finding the perfect match: Hydrogels for treatment of central nervous system injury, Mater. Today Adv., 2020, 6, 100039.

29 A. D. Gaudet and L. K. Fonken, Glial cells shape pathology and repair after spinal cord injury, Neurotherapeutics, 2018, 15(3), 554-577.

30 M. Pekny, U. Wilhelmsson, T. Tatlisumak and M. Pekna, Astrocyte activation and reactive gliosis: A new target in stroke?, Neurosci. Lett., 2019, 689, 45-55.

31 I. B. Wanner, M. A. Anderson, B. Song, J. Levine, A. Fernandez and Z. Gray-Thompson, et al., Glial scar borders are formed by newly proliferated, elongated astrocytes that interact to corral inflammatory and fibrotic cells via STAT3-dependent mechanisms after spinal cord injury, J. Neurosci., 2013, 33(31), 12870-12886.

32 M. A. Anderson, J. E. Burda, Y. Ren, Y. Ao, T. M. O'Shea and R. Kawaguchi, et al., Astrocyte scar formation aids central nervous system axon regeneration, Nature, 2016, 532(7598), 195-200.

33 K. A. Kigerl, J. C. Gensel, D. P. Ankeny, J. K. Alexander, D. J. Donnelly and P. G. Popovich, Identification of two distinct macrophage subsets with divergent effects causing either neurotoxicity or regeneration in the injured mouse spinal cord, J. Neurosci., 2009, 29(43), 13435-13444.

34 Y. Ma, J. Wang, Y. Wang and G. Y. Yang, The biphasic function of microglia in ischemic stroke, Prog. Neurobiol., 2017, 157, 247-272.

35 D. M. McTigue, P. Wei and B. T. Stokes, Proliferation of NG2positive cells and altered oligodendrocyte numbers in the contused rat spinal cord, J. Neurosci., 2001, 21(10), 3392-3400.

36 X. He, Y. Li, H. Lu, Z. Zhang, Y. Wang and G. Y. Yang, Netrin-1 overexpression promotes white matter repairing and remodeling after focal cerebral ischemia in mice, J. Cereb. Blood Flow Metab., 2013, 33(12), 1921-1927.

37 S. Liu, T. Schackel, N. Weidner and R. Puttagunta, Biomaterial-supported cell transplantation treatments for spinal cord injury: Challenges and perspectives, Front. Cell. Neurosci., 2017, 11, 430.
38 D. D. Pearse and D. J. Barakat, Cellular repair strategies for spinal cord injury, Expert Opin. Biol. Ther., 2006, 6(7), 639-652.

39 A. M. Parr, I. Kulbatski, T. Zahir, X. Wang, C. Yue and A. Keating, et al., Transplanted adult spinal cord-derived neural stem/progenitor cells promote early functional recovery after rat spinal cord injury, Neuroscience, 2008, 155(3), 760-770.

40 W. Zakrzewski, M. Dobrzynski, M. Szymonowicz and Z. Rybak, Stem cells: Past, present, and future, Stem Cell Res. Ther., 2019, 10(1), 68.

41 A. R. Massensini, H. Ghuman, L. T. Saldin, C. J. Medberry, T. J. Keane and F. J. Nicholls, et al., Concentrationdependent rheological properties of ECM hydrogel for intracerebral delivery to a stroke cavity, Acta Biomater., 2015, 27, 116-130.

42 A. Mellati and J. Akhtari, Injectable hydrogels: A review of injectability mechanisms and biomedical applications, Res. Mol. Med., 2019, 1-14.

43 Y. Sun, D. Nan, H. Jin and X. Qu, Recent advances of injectable hydrogels for drug delivery and tissue engineering applications, Polym. Test., 2020, 81, 106283.

44 P. J. Kondiah, Y. E. Choonara, P. P. Kondiah, T. Marimuthu, P. Kumar and L. C. du Toit, et al., A review of injectable polymeric hydrogel systems for application in bone tissue engineering, Molecules, 2016, 21(11), 1580.

45 K. Y. Choi, H. S. Han, E. S. Lee, J. M. Shin, B. D. Almquist and D. S. Lee, et al., Hyaluronic acid-based activatable nanomaterials for stimuli-responsive imaging and therapeutics: Beyond CD44-mediated drug delivery, Adv. Mater., 2019, e1803549.

46 S. Naahidi, M. Jafari, M. Logan, Y. Wang, Y. Yuan and H. Bae, et al., Biocompatibility of hydrogel-based scaffolds for tissue engineering applications, Biotechnol. Adv., 2017, 35(5), 530-544.

47 B. Saleh, H. K. Dhaliwal, R. Portillo-Lara, E. Shirzaei Sani, R. Abdi and M. M. Amiji, et al., Local immunomodulation using an adhesive hydrogel loaded with miRNA-laden nanoparticles promotes wound healing, Small, 2019, e1902232.

48 A. Gupta, S. M. Briffa, S. Swingler, H. Gibson, V. Kannappan and G. Adamus, et al., Synthesis of silver nanoparticles using curcumin-cyclodextrins loaded into bacterial cellulose-based hydrogels for wound dressing applications, Biomacromolecules, 2020, 1802-1811.

49 X. Du, Y. Liu, X. Wang, H. Yan, L. Wang and L. Qu, et al., Injectable hydrogel composed of hydrophobically modified chitosan/oxidized-dextran for wound healing, Mater. Sci. Eng., C, 2019, 104, 109930.

50 N. Annabi, D. Rana, E. Shirzaei Sani, R. Portillo-Lara, J. L. Gifford and M. M. Fares, et al., Engineering a sprayable and elastic hydrogel adhesive with antimicrobial properties for wound healing, Biomaterials, 2017, 139, 229-243.

$51 \mathrm{~J}$. Li and G. Lepski, Cell transplantation for spinal cord injury: A systematic review, BioMed Res. Int., 2013, 2013, 786475. 
52 L. M. Marquardt and S. C. Heilshorn, Design of injectable materials to improve stem cell transplantation, Curr. Stem Cell Rep., 2016, 2(3), 207-220.

53 S. Budday, G. Sommer, C. Birkl, C. Langkammer, J. Haybaeck and J. Kohnert, et al., Mechanical characterization of human brain tissue, Acta Biomater., 2017, 48, 319-340.

54 S. M. Willerth and S. E. Sakiyama-Elbert, Approaches to neural tissue engineering using scaffolds for drug delivery, Adv. Drug Delivery Rev., 2007, 59(4-5), 325-338.

55 D. Macaya, K. K. Ng and M. Spector, Injectable collagenGenipin gel for the treatment of spinal cord injury: In vitro studies, Adv. Funct. Mater., 2011, 21(24), 4788-4797.

56 E. Ansorena, P. De Berdt, B. Ucakar, T. Simon-Yarza, D. Jacobs and O. Schakman, et al., Injectable alginate hydrogel loaded with GDNF promotes functional recovery in a hemisection model of spinal cord injury, Int. J. Pharm., 2013, 455(1-2), 148-158.

57 M. C. Catoira, L. Fusaro, D. Di Francesco, M. Ramella and F. Boccafoschi, Overview of natural hydrogels for regenerative medicine applications, J. Mater. Sci.: Mater. Med., 2019, 30(10), 115.

58 E. G. Norris, D. Dalecki and D. C. Hocking, Acoustic modification of collagen hydrogels facilitates cellular remodeling, Mater Today Bio, 2019, 3, 100018.

59 K. Matsumoto, Y. Li, C. Jakuba, Y. Sugiyama, T. Sayo and M. Okuno, et al., Conditional inactivation of Has2 reveals a crucial role for hyaluronan in skeletal growth, patterning, chondrocyte maturation and joint formation in the developing limb, Development, 2009, 136(16), 2825-2835.

60 H. Hamedi, S. Moradi, S. M. Hudson and A. E. Tonelli, Chitosan based hydrogels and their applications for drug delivery in wound dressings: A review, Carbohydr. Polym., 2018, 199, 445-460.

61 H. Li, Z. Qi, S. Zheng, Y. Chang, W. Kong and C. Fu, et al., The application of hyaluronic acid-based hydrogels in bone and cartilage tissue engineering, Adv. Mater. Sci. Eng., 2019, 2019, 1-12.

62 C. E. Semino, Self-assembling peptides: From bio-inspired materials to bone regeneration, J. Dent. Res., 2008, 87(7), 606-616.

63 O. Steward, B. Zheng and M. Tessier-Lavigne, False resurrections: Distinguishing regenerated from spared axons in the injured central nervous system, J. Comp. Neurol., 2003, 459(1), 1-8.

64 H. Nomura, Y. Katayama, M. S. Shoichet and C. H. Tator, Complete spinal cord transection treated by implantation of a reinforced synthetic hydrogel channel results in syringomyelia and caudal migration of the rostral stump, Neurosurgery, 2006, 53(1), 183-192.

65 B. M. Gillette, J. A. Jensen, B. Tang, G. J. Yang, A. BazarganLari and M. Zhong, et al., In situ collagen assembly for integrating microfabricated three-dimensional cell-seeded matrices, Nat. Mater., 2008, 7(8), 636-640.

66 M. Tsintou, K. Dalamagkas and A. Seifalian, Injectable hydrogel versus plastically compressed collagen scaffold for central nervous system applications, Int. J. Biomater., 2018, 2018, 3514019.

67 M. M. Pakulska, B. G. Ballios and M. S. Shoichet, Injectable hydrogels for central nervous system therapy, Biomed. Mater., 2012, 7(2), 024101.

68 E. Bellotti, A. L. Schilling, S. R. Little and P. Decuzzi, Injectable thermoresponsive hydrogels as drug delivery system for the treatment of central nervous system disorders: A review, J. Controlled Release, 2020, 329, 16-35.

69 S. Bai, W. Zhang, Q. Lu, Q. Ma, D. L. Kaplan and H. Zhu, Silk nanofiber hydrogels with tunable modulus to regulate nerve stem cell fate, J. Mater. Chem. B, 2014, 2(38), 6590-6600.

70 C. P. Addington, S. Dharmawaj, J. M. Heffernan, R. W. Sirianni and S. E. Stabenfeldt, Hyaluronic acid-laminin hydrogels increase neural stem cell transplant retention and migratory response to SDF-1alpha, Matrix Biol., 2017, 60-61, 206-216.

71 S. K. Seidlits, J. Liang, R. D. Bierman, A. Sohrabi, J. Karam and S. M. Holley, et al., Peptide-modified, hyaluronic acidbased hydrogels as a 3D culture platform for neural stem/ progenitor cell engineering, J. Biomed. Mater. Res. A, 2019, 107(4), 704-718.

72 K. H. Bae, L. S. Wang and M. Kurisawa, Injectable biodegradable hydrogels: Progress and challenges, J. Mater. Chem. B, 2013, 1(40), 5371-5388.

73 P. van de Wetering, A. T. Metters, R. G. Schoenmakers and J. A. Hubbell, Poly(ethylene glycol) hydrogels formed by conjugate addition with controllable swelling, degradation, and release of pharmaceutically active proteins, J. Controlled Release, 2005, 102(3), 619-627.

74 M. Kurisawa, F. Lee, L.-S. Wang and J. E. Chung, Injectable enzymatically crosslinked hydrogel system with independent tuning of mechanical strength and gelation rate for drug delivery and tissue engineering, J. Mater. Chem., 2010, 20(26), 5371-5375.

75 E. Verheyen, L. Delain-Bioton, S. van der Wal, N. el Morabit, A. Barendregt and W. E. Hennink, et al., Conjugation of methacrylamide groups to a model protein via a reducible linker for immobilization and subsequent triggered release from hydrogels, Macromol. Biosci., 2010, 10(12), 1517-1526.

76 J. Lee, C. Y. Tan, S. K. Lee, Y. H. Kim and K. Y. Lee, Controlled delivery of heat shock protein using an injectable microsphere/hydrogel combination system for the treatment of myocardial infarction, J. Controlled Release, 2009, 137(3), 196-202.

77 B. Soontornworajit, J. Zhou, Z. Zhang and Y. Wang, Aptamer-functionalized in situ injectable hydrogel for controlled protein release, Biomacromolecules, 2010, 11(10), 2724-2730.

78 M. P. Lutolf, G. P. Raeber, A. H. Zisch, N. Tirelli and J. A. Hubbell, Cell-responsive synthetic hydrogels, Adv. Mater., 2003, 15(11), 888-892.

79 K. L. Niece, J. D. Hartgerink, J. J. J. M. Donners and S. I. Stupp, Self-assembly combining two bioactive peptideamphiphile molecules into nanofibers by electrostatic attraction, J. Am. Chem. Soc., 2003, 125(24), 7146-7147. 
80 G. A. Silva, C. Czeisler, K. L. Niece, E. Beniash, D. A. Harrington and J. A. Kessler, et al., Selective differentiation of neural progenitor cells by high-epitope density nanofibers, Science, 2004, 303, 1352-1355.

81 M. C. Jin, Z. A. Medress, T. D. Azad, V. M. Doulames and A. Veeravagu, Stem cell therapies for acute spinal cord injury in humans: A review, Neurosurg. Focus, 2019, 46(3), E10.

82 S. L. Payne, A. Tuladhar, J. M. Obermeyer, B. V. Varga, C. J. Teal and C. M. Morshead, et al., Initial cell maturity changes following transplantation in a hyaluronan-based hydrogel and impacts therapeutic success in the strokeinjured rodent brain, Biomaterials, 2019, 192, 309-322.

83 P. Moshayedi, L. R. Nih, I. L. Llorente, A. R. Berg, J. Cinkornpumin and W. E. Lowry, et al., Systematic optimization of an engineered hydrogel allows for selective control of human neural stem cell survival and differentiation after transplantation in the stroke brain, Biomaterials, 2016, 105, 145-155.

84 M. R. McCrary, K. Jesson, Z. Z. Wei, M. Logun, C. Lenear and S. Tan, et al., Cortical transplantation of brainmimetic glycosaminoglycan scaffolds and neural progenitor cells promotes vascular regeneration and functional recovery after ischemic stroke in mice, Adv. Healthcare Mater., 2020, 9(5), e1900285.

85 T. Osanai, S. Kuroda, H. Yasuda, Y. Chiba, K. Maruichi and M. Hokari, et al., Noninvasive transplantation of bone marrow stromal cells for ischemic stroke: Preliminary study with a thermoreversible gelation polymer hydrogel, Neurosurgery, 2010, 66(6), 1140-1147; discussion 7.

86 I. Osama, N. Gorenkova, C. M. McKittrick, T. Wongpinyochit, A. Goudie and F. P. Seib, et al., In vitro studies on spaceconforming self-assembling silk hydrogels as a mesenchymal stem cell-support matrix suitable for minimally invasive brain application, Sci. Rep., 2018, 8(1), 13655.

87 L. Xu, J. Ryu, H. Hiel, A. Menon, A. Aggarwal and E. Rha, et al., Transplantation of human oligodendrocyte progenitor cells in an animal model of diffuse traumatic axonal injury: Survival and differentiation, Stem Cell Res. Ther., 2015, 6, 93.

88 P. J. Reddig and R. L. Juliano, Clinging to life cell to matrix adhesion and cell survival, Cancer Metastasis Rev., 2005, 24, 425-439.

89 F. Barnabe-Heider and J. Frisen, Stem cells for spinal cord repair, Cell Stem Cell, 2008, 3(1), 16-24.

90 S. Tavakol, R. Saber, E. Hoveizi, H. Aligholi, J. Ai and S. M. Rezayat, Chimeric self-assembling nanofiber containing bone marrow homing peptide's motif induces motor neuron recovery in animal model of chronic spinal cord injury; an in vitro and in vivo investigation, Mol. Neurobiol., 2016, 53, 3298-3308.

91 Z. Wang, J. Wang, Y. Jin, Z. Luo, W. Yang and H. Xie, et al., A neuroprotective sericin hydrogel as an effective neuronal cell carrier for the repair of ischemic stroke, ACS Appl. Mater. Interfaces, 2015, 7(44), 24629-24640.

92 N. Rouleau, W. L. Cantley, V. Liaudanskaya, A. Berk, C. Du and W. Rusk, et al., A long-living bioengineered neural tissue platform to study neurodegeneration, Macromol. Biosci., 2020, 20(3), e2000004.

93 M. Naruse, K. Shibasaki, S. Yokoyama, M. Kurachi and Y. Ishizaki, Dynamic changes of CD44 expression from progenitors to subpopulations of astrocytes and neurons in developing cerebellum, PLoS One, 2013, 8(1), e53109.

94 A. Konopka, A. Zeug, A. Skupien, B. Kaza, F. Mueller and A. Chwedorowicz, et al., Cleavage of hyaluronan and CD44 adhesion molecule regulate astrocyte morphology via Rac1 signalling, PLoS One, 2016, 11(5), e0155053.

95 R. Sawada, A. Nakano-Doi, T. Matsuyama, N. Nakagomi and T. Nakagomi, CD44 expression in stem cells and niche microglia/macrophages following ischemic stroke, Stem Cell Investig., 2020, 7, 4.

96 T. Fujimoto, H. Kawashima, T. Tanaka, M. Hirose, N. Toyama-Sorimachi and Y. Matsuzawa, et al., CD44 binds a chondrotin sulfate proteoglycan, aggrecan, Int. Immunol., 2001, 13, 359-366.

97 M. S. Kurtis, B. P. Tu, O. A. Gaya, J. Mollenhauer, W. Knudson, R. F. Loeser, C. B. Knudson and R. L. Sah, Mechanisms of chondrocyte adhesion to cartilage role of pl-integrins, CD44, and annexin V, J. Orthopaed. Res., 2001, 19(6), 1122-1130.

98 S. Koutsopoulos and S. Zhang, Long-term threedimensional neural tissue cultures in functionalized selfassembling peptide hydrogels, matrigel and collagen I, Acta Biomater., 2013, 9(2), 5162-5169.

99 H. Ponta, L. Sherman and P. A. Herrlich, CD44: From adhesion molecules to signalling regulators, Nat. Rev. Mol. Cell Biol., 2003, 4(1), 33-45.

100 M. J. Caicco, T. Zahir, A. J. Mothe, B. G. Ballios, A. J. Kihm and C. H. Tator, et al., Characterization of hyaluronanmethylcellulose hydrogels for cell delivery to the injured spinal cord, J. Biomed. Mater. Res. A, 2013, 101(5), 1472-1477.

101 R. Ju, Y. Wen, R. Gou, Y. Wang and Q. Xu, The experimental therapy on brain ischemia by improvement of local angiogenesis with tissue engineering in the mouse, Cell Transplant., 2014, 23(Suppl 1), S83-S95.

$102 \mathrm{~J}$. Qu and H. Zhang, Roles of mesenchymal stem cells in spinal cord injury, Stem Cells Int., 2017, 2017, 5251313.

103 A. Shao, S. Tu, J. Lu and J. Zhang, Crosstalk between stem cell and spinal cord injury: Pathophysiology and treatment strategies, Stem Cell Res. Ther., 2019, 10(1), 238.

104 T. Yamashita and K. Abe, Recent progress in therapeutic strategies for ischemic stroke, Cell Transplant., 2016, 25(5), 893-898.

105 A. J. Mothe, R. Y. Tam, T. Zahir, C. H. Tator and M. S. Shoichet, Repair of the injured spinal cord by transplantation of neural stem cells in a hyaluronanbased hydrogel, Biomaterials, 2013, 34(15), 3775-3783.

106 T. H. Perera, X. Lu, S. M. Howell, Y. E. Kurosu and L. A. Smith Callahan, Combination of IKVAV, LRE, and GPQGIWGQ bioactive signaling peptides increases human induced pluripotent stem cell derived neural stem cells 
extracellular matrix remodeling and neurite extension, Adv. BioSyst., 2020, e2000084.

107 S. A. Geissler, A. L. Sabin, R. R. Besser, O. M. Gooden, B. D. Shirk and Q. M. Nguyen, et al., Biomimetic hydrogels direct spinal progenitor cell differentiation and promote functional recovery after spinal cord injury, J. Neural Eng., 2018, $15(2), 025004$.

108 J. Nicolas, S. Magli, L. Rabbachin, S. Sampaolesi, F. Nicotra and L. Russo, 3D Extracellular matrix mimics: Fundamental concepts and role of materials chemistry to influence stem cell fate, Biomacromolecules, 2020, 21(6), 1968-1994.

109 R. Patel, M. Santhosh, J. K. Dash, R. Karpoormath, A. Jha and J. Kwak, et al., Ile-Lys-Val-ala-Val (IKVAV) peptide for neuronal tissue engineering, Polym. Adv. Technol., 2019, 30(1), 4-12.

110 F. Tabatabaei, Z. Aghamohammadi and L. Tayebi, In vitro and in vivo effects of concentrated growth factor on cells and tissues, J. Biomed. Mater. Res. A, 2020, 108(6), 1338-1350.

111 A. Younsi, G. Zheng, M. Scherer, L. Riemann, H. Zhang and M. Tail, et al., Three growth factors induce proliferation and differentiation of neural precursor cells in vitro and support cell-transplantation after spinal cord injury in vivo, Stem Cells Int., 2020, 2020, 10046-10064.

112 G. A. Silva, C. Czeisler, K. L. Niece, E. Beniash, D. A. Harrington and J. A. Kessler, et al., Selective differentiation of neural progenitor cells by high-epitope density nanofibers, Science, 2004, 303(5662), 1352-1355.

113 N. Mukherjee, A. Adak and S. Ghosh, Recent trends in the development of peptide and protein-based hydrogel therapeutics for the healing of CNS injury, Soft Matter, 2020, 10046-10064.

114 W. Sun, T. Incitti, C. Migliaresi, A. Quattrone, S. Casarosa and A. Motta, Viability and neuronal differentiation of neural stem cells encapsulated in silk fibroin hydrogel functionalized with an IKVAV peptide, J. Tissue Eng. Regen. Med., 2017, 11(5), 1532-1541.

115 L. Fan, C. Liu, X. Chen, Y. Zou, Z. Zhou and C. Lin, et al., Directing induced pluripotent stem cell derived neural stem cell fate with a three-dimensional biomimetic hydrogel for spinal cord injury repair, ACS Appl. Mater. Interfaces, 2018, 10(21), 17742-17755.

116 D. Ye and A. Peramo, Implementing tissue engineering and regenerative medicine solutions in medical implants, Br. Med. Bull., 2014, 109, 3-18.

117 H. Altinova, S. Hammes, M. Palm, P. Achenbach, J. Gerardo-Nava and R. Deumens, et al., Dense fibroadhesive scarring and poor blood vessel-maturation hamper the integration of implanted collagen scaffolds in an experimental model of spinal cord injury, Biomed. Mater., 2020, 15(1), 015012.

118 D. Tukmachev, S. Forostyak, Z. Koci, K. Zaviskova, I. Vackova and K. Vyborny, et al., Injectable extracellular matrix hydrogels as scaffolds for spinal cord injury repair, Tissue Eng., Part A, 2016, 22(3-4), 306-317.
119 V. R. King, A. Alovskaya, D. Y. Wei, R. A. Brown and J. V. Priestley, The use of injectable forms of fibrin and fibronectin to support axonal ingrowth after spinal cord injury, Biomaterials, 2010, 31(15), 4447-4456.

120 Y. Liu, H. Ye, K. Satkunendrarajah, G. S. Yao, Y. Bayon and M. G. Fehlings, A self-assembling peptide reduces glial scarring, attenuates post-traumatic inflammation and promotes neurological recovery following spinal cord injury, Acta Biomater., 2013, 9(9), 8075-8088.

121 L. R. Nih, E. Sideris, S. T. Carmichael and T. Segura, Injection of microporous annealing particle (MAP) hydrogels in the stroke cavity reduces gliosis and inflammation and promotes NPC migration to the lesion, Adv. Mater., 2017, 29(32), 1606471.

122 L. T. A. Hong, Y. M. Kim, H. H. Park, D. H. Hwang, Y. Cui and E. M. Lee, et al., An injectable hydrogel enhances tissue repair after spinal cord injury by promoting extracellular matrix remodeling, Nat. Commun., 2017, 8(1), 533.

123 A. des Rieux, P. De Berdt, E. Ansorena, B. Ucakar, J. Damien and O. Schakman, et al., Vascular endothelial growth factor-loaded injectable hydrogel enhances plasticity in the injured spinal cord, J. Biomed. Mater. Res. A, 2014, 102(7), 2345-2355.

124 H. Ghuman, M. Gerwig, F. J. Nicholls, J. R. Liu, J. Donnelly and S. F. Badylak, et al., Long-term retention of ECM hydrogel after implantation into a sub-acute stroke cavity reduces lesion volume, Acta Biomater., 2017, 63, 50-63.

125 E. A. Huebner and S. M. Strittmatter, Axon regeneration in the peripheral and central nervous systems, Res. Probl. Cell Differ., 2009, 48, 339-351.

126 K. E. Dow, S. E. Mirski, J. C. Roder and R. J. Riopelle, Neuronal proteoglycans: Biosynthesis and functional interaction with neurons in vitro, J. Neurosci., 1988, 8(9), 3278-3289.

127 C. Darian-Smith, Synaptic plasticity, neurogenesis, and functional recovery after spinal cord injury, Neuroscientist, 2009, 15(2), 149-165.

128 F. A. Somaa, T. Y. Wang, J. C. Niclis, K. F. Bruggeman, J. A. Kauhausen and H. Guo, et al., Peptide-based scaffolds support human cortical progenitor graft integration to reduce atrophy and promote functional repair in a model of stroke, Cell Rep., 2017, 20(8), 1964-1977.

129 Y. Wang, M. J. Cooke, C. M. Morshead and M. S. Shoichet, Hydrogel delivery of erythropoietin to the brain for endogenous stem cell stimulation after stroke injury, Biomaterials, 2012, 33(9), 2681-2692.

130 Q. Wang, Y. He, Y. Zhao, H. Xie, Q. Lin and Z. He, et al., A thermosensitive heparin-poloxamer hydrogel bridges aFGF to treat spinal cord injury, ACS Appl. Mater. Interfaces, 2017, 9(8), 6725-6745.

131 V. Gupta, D. V. Lyne, A. D. Laflin, T. A. Zabel, M. Barragan and J. T. Bunch, et al., Microsphere-based osteochondral scaffolds carrying opposing gradients of decellularized cartilage and demineralized bone matrix, ACS Biomater. Sci. Eng., 2017, 3(9), 1955-1963. 
132 C. R. Rowland, K. A. Glass, A. R. Ettyreddy, C. C. Gloss, J. R. L. Matthews and N. P. T. Huynh, et al., Regulation of decellularized tissue remodeling via scaffold-mediated lentiviral delivery in anatomically-shaped osteochondral constructs, Biomaterials, 2018, 177, 161-175.

133 L. Sang, Y. Liu, W. Hua, K. Xu, G. Wang and W. Zhong, et al., Thermally sensitive conductive hydrogel using amphiphilic crosslinker self-assembled carbon nanotube to enhance neurite outgrowth and promote spinal cord regeneration, RSC Adv., 2016, 6(31), 26341-26351.

134 R. C. Cornelison, E. J. Gonzalez-Rothi, S. L. Porvasnik, S. M. Wellman, J. H. Park and D. D. Fuller, et al., Injectable hydrogels of optimized acellular nerve for injection in the injured spinal cord, Biomed. Mater., 2018, 13(3), 034110.

135 H. Ghuman, C. Mauney, J. Donnelly, A. R. Massensini, S. F. Badylak and M. Modo, Biodegradation of ECM hydrogel promotes endogenous brain tissue restoration in a rat model of stroke, Acta Biomater., 2018, 80, 66-84.

136 L. H. Nguyen, M. Gao, J. Lin, W. Wu, J. Wang and S. Y. Chew, Three-dimensional aligned nanofibershydrogel scaffold for controlled non-viral drug/gene delivery to direct axon regeneration in spinal cord injury treatment, Sci. Rep., 2017, 7(1), 42212.

137 P. Lu, K. Takai, V. M. Weaver and Z. Werb, Extracellular matrix degradation and remodeling in development and disease, Cold Spring Harb. Perspect. Biol., 2011, 3(12), a005058.

138 G. A. Hudalla, T. S. Eng and W. L. Murphy, An approach to modulate degradation and mesenchymal stem cell behavior in poly(ethylene glycol) networks, Biomacromolecules, 2008, 9(3), 842-849.

139 K. Ravina, D. I. Briggs, S. Kislal, Z. Warraich, T. Nguyen and R. K. Lam, et al., Intracerebral delivery of brain-derived neurotrophic factor using HyStem((R))-C hydrogel implants improves functional recovery and reduces neuroinflammation in a rat model of ischemic stroke, Int. J. Mol. Sci., 2018, 19(12), 3782.

140 D. J. Cook, C. Nguyen, H. N. I. L. L. Chun, A. S. Chiu and M. Machnicki, et al., Hydrogel-delivered brain-derived neurotrophic factor promotes tissue repair and recovery after stroke, J. Cereb. Blood Flow Metab., 2017, 37(3), 1030-1045.

141 A. A. Foster, L. M. Marquardt and S. C. Heilshorn, The diverse roles of hydrogel mechanics in injectable stem cell transplantation, Curr. Opin. Chem. Eng., 2017, 15, 15-23.

142 C. G. Liew, H. Moore, L. Ruban, N. Shah, K. Cosgrove and M. Dunne, et al., Human embryonic stem cells: Possibilities for human cell transplantation, Ann. Med., 2005, 37(7), 521-532.

143 M. F. Azari, L. Mathias, E. Ozturk, D. S. Cram, R. L. Boyd and S. Petratos, Mesenchymal stem cells for treatment of CNS injury, Curr. Neuropharmacol., 2010, 8(4), 316-323.

144 M. G. Cefalo, A. Carai, E. Miele, A. Po, E. Ferretti and A. Mastronuzzi, et al., Human iPSC for therapeutic approaches to the nervous system: Present and future applications, Stem Cells Int., 2016, 2016, 4869071.
145 G. W. Hawryluk, A. Mothe, J. Wang, S. Wang, C. Tator and M. G. Fehlings, An in vivo characterization of trophic factor production following neural precursor cell or bone marrow stromal cell transplantation for spinal cord injury, Stem Cells Dev., 2012, 21(12), 2222-2238.

146 C. Lutton, Y. W. Young, R. Williams, A. C. Meedeniya, A. Mackay-Sim and B. Goss, Combined VEGF and PDGF treatment reduces secondary degeneration after spinal cord injury, J. Neurotrauma, 2012, 29(5), 957-970.

147 M. V. Sofroniew, Molecular dissection of reactive astrogliosis and glial scar formation, Trends Neurosci., 2009, 32(12), 638-647.

148 S. Karimi-Abdolrezaee and R. Billakanti, Reactive astrogliosis after spinal cord injury-beneficial and detrimental effects, Mol. Neurobiol., 2012, 46(2), 251-264.

149 G. Yiu and Z. He, Glial inhibition of CNS axon regeneration, Nat. Rev. Neurosci., 2006, 7(8), 617-627.

150 A. Rolls, R. Shechter and M. Schwartz, The bright side of the glial scar in CNS repair, Nat. Rev. Neurosci., 2009, 10(3), 235-241.

151 V. Gallo and B. Deneen, Glial development: The crossroads of regeneration and repair in the CNS, Neuron, 2014, 83(2), 283-308.

152 D. Gupta, C. H. Tator and M. S. Shoichet, Fast-gelling injectable blend of hyaluronan and methylcellulose for intrathecal, localized delivery to the injured spinal cord, Biomaterials, 2006, 27(11), 2370-2379.

153 K. Anderson, S. Aito, M. Atkins, F. Biering-Sørensen, S. Charlifue and A. Curt, et al., Functional recovery measures for spinal cord injury an evidence-based review for clinical practice and research, J. Spinal Cord Med., 2008, 31(2), 133-144.

154 W. S. Redfern, A. Dymond, I. Strang, S. Storey, C. Grant and L. Marks, et al., The functional observational battery and modified Irwin test as global neurobehavioral assessments in the rat: Pharmacological validation data and a comparison of methods, J. Pharmacol. Toxicol. Methods, 2019, 98, 106591.

155 R. U. Ahmed, M. Alam and Y. P. Zheng, Experimental spinal cord injury and behavioral tests in laboratory rats, Heliyon, 2019, 5(3), e01324.

156 M. R. Detloff, L. C. Fisher, R. J. Deibert and D. M. Basso, Acute and chronic tactile sensory testing after spinal cord injury in rats, J. Vis. Exp., 2012, 62, e3247.

157 K. Gale, H. Kerasidis and J. R. Wrathall, Spinal cord contusion in the rat Behavioral analysis of functional neurologic impairment, Exp. Neurol., 1985, 88(1), 123-134.

158 W. Yu, J. X. Hao, X. J. Xu, J. Saydoff, A. Haegerstrand and T. Hökfelt, et al., Long-term alleviation of allodynia-like behaviors by intrathecal implantation of bovine chromaffin cells in rats with spinal cord injury, Pain, 1998, 74(2-3), 115-122.

159 D. M. Basso, M. S. Beattie and J. C. Bresnahan, A sensitive and reliable locomotor rating scale for open field testing in rats, J. Neurotrauma, 1995, 12(1), 1-21. 
160 G. Laviola, G. Renna, G. Bignami and V. Cuomo, Ontogenetic and pharmacological dissociation of various components of locomotor activity and habituation in the rat, Int. J. Dev. Neurosci., 1988, 6(5), 431-438.

161 L. Prut and C. Belzung, The open field as a paradigm to measure the effects of drugs on anxiety-like behaviors: A review, Eur. J. Pharmacol., 2003, 463(1-3), 3-33.

162 S. H. Wang, Z. J. Zhang, Y. J. Guo, G. J. Teng and B. A. Chen, Hippocampal neurogenesis and behavioural studies on adult ischemic rat response to chronic mild stress, Behav. Brain Res., 2008, 189(1), 9-16.

163 A. Sarkaki, Y. Farbood, M. Badavi, L. Khalaj, F. Khodagholi and G. Ashabi, Metformin improves anxiety-like behaviors through AMPK-dependent regulation of autophagy following transient forebrain ischemia, Metab. Brain Dis., 2015, 30(5), 1139-1150.

164 N. Xu, E. Akesson, L. Holmberg and E. Sundstrom, A sensitive and reliable test instrument to assess swimming in rats with spinal cord injury, Behav. Brain Res., 2015, 291, 172-183.

$165 \mathrm{~J}$. Ruan and Y. Yao, Behavioral tests in rodent models of stroke, Brain Hemorrhages, 2020, 1(4), 171-184.

166 M. W. McDonald, S. E. Black, D. A. Copland, D. Corbett, R. M. Dijkhuizen and T. D. Farr, et al., Cognition in stroke rehabilitation and recovery research: Consensus-based core recommendations from the second Stroke Recovery and Rehabilitation Roundtable, Int. J. Stroke, 2019, 14(8), 774-782.

167 R. G. M. Morris, Spatial localization does not require the presence of local cues, Learn. Motivat., 1981, 12(2), 239-260.

168 L. Kokkinidis, M. D. Walsh, R. Lahue and H. Anisman, Tolerance to d-amphetamine Behavioral specificity, Life Sci., 1976, 18(9), 913-917.

169 J. P. Aggleton, One-trial object recognition by rats, Q. J. Exp. Psychol. Sect. B, 1985, 37(4), 279-294.

170 D. S. Olton, C. Collison and M. A. Werz, Spatial memory and radial arm maze performance of rats, Learn. Motivat., 1977, 8(3), 289-314.

171 A. Patar, P. Dockery, S. McMahon and L. Howard, Ex vivo rat transected spinal cord slices as a model to assess lentiviral vector delivery of neurotrophin-3 and short hairpin RNA against NG2, Biology, 2020, 9(3), 54.

172 A. P. Haring, H. Sontheimer and B. N. Johnson, Microphysiological human brain and neural systems-on-a-chip: Potential alternatives to small animal models and emerging platforms for drug discovery and personalized medicine, Stem Cell Rev. Rep., 2017, 13(3), 381-406. 